San Jose State University

SJSU ScholarWorks

Master's Theses

Master's Theses and Graduate Research

1994

\title{
The perception of six women with disabilities of their self-directed occupational role as dancer
}

Pamela Hope Dent

San Jose State University

Follow this and additional works at: https://scholarworks.sjsu.edu/etd_theses

\section{Recommended Citation}

Dent, Pamela Hope, "The perception of six women with disabilities of their self-directed occupational role as dancer" (1994). Master's Theses. 830.

DOI: https://doi.org/10.31979/etd.3q4t-f38s

https://scholarworks.sjsu.edu/etd_theses/830

This Thesis is brought to you for free and open access by the Master's Theses and Graduate Research at SJSU ScholarWorks. It has been accepted for inclusion in Master's Theses by an authorized administrator of SJSU ScholarWorks. For more information, please contact scholarworks@sjsu.edu. 


\section{INFORMATION TO USERS}

This manuscript has been reproduced from the microfilm master. UMI films the text directly from the original or copy submitted. Thus, some thesis and dissertation copies are in typewriter face, while others may be from any type of computer printer.

The quality of this reproduction is dependent upon the quality of the copy submitted. Broken or indistinct print, colored or poor quality illustrations and photographs, print bleedthrough, substandard margins, and improper alignment can adversely affect reproduction.

In the unlikely event that the author did not send UMI a complete manuscript and there are missing pages, these will be noted. Also, if unauthorized copyright material had to be removed, a note will indicate the deletion.

Oversize materials (e.g., maps, drawings, charts) are reproduced by sectioning the original, beginning at the upper left-hand corner and continuing from left to right in equal sections with small overlaps. Each original is also photographed in one exposure and is included in reduced form at the back of the book.

Photographs included in the original manuscript have been reproduced xerographically in this copy. Higher quality $6^{\prime \prime} \times 9^{\prime \prime}$ black and white photographic prints are available for any photographs or illustrations appearing in this copy for an additional charge. Contact UMI directly to order.

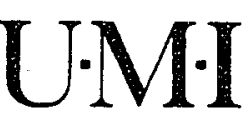

University Microfilms international

A Bell \& Howell Information Company

300 North Zeeb Road. Ann Arbor. MI 48106-1346 USA

$313 / 761-4700,800 / 521-0600$ 
- 
Order Number 1359013

The perception of six women with disabilities of their self-directed occupational role as dancer

\section{Dent, Pamela Hope, M.S.}

San Jose State University, 1994

Copyright (C1994 by Dent, Pamela Hope. All rights reserved.

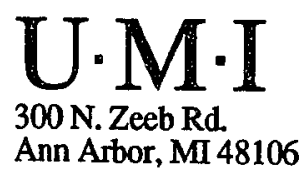





\title{
THE PERCEPTION OF SIX WOMEN WITH DISABILITIES
}

\section{OF THEIR SELF-DIRECTED OCCUPATIONAL ROLE AS DANCER}

\author{
A Thesis \\ Presented to \\ The Faculty of the Department of Occupational Therapy \\ San Jose State University \\ In partial Fulfillment \\ of the Requirements for the Degree \\ Master of Sciences
}

By

Pamela Hope Dent, O.T.R.

August, 1994 
(C) 1994

Pamela Hope Dent, O.T.R.

ALL RIGHTS RESERVED 
APPROVED FOR THE DEPARTMENT OF OCCUPATIONAL THERAPY
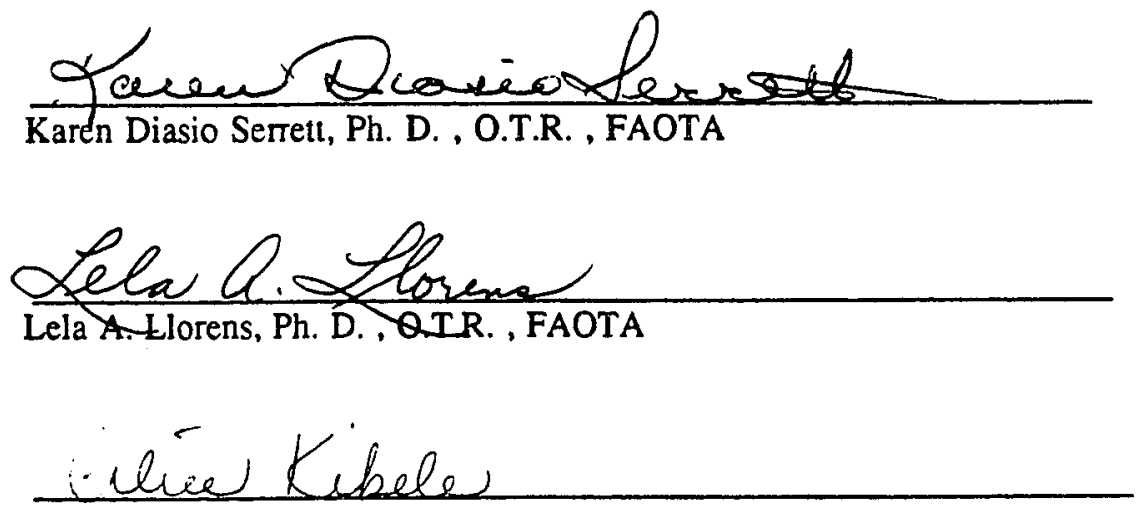

Alice Kibele, M.A. , O.T.R.

APPROVED FOR THE UNIVERSITY

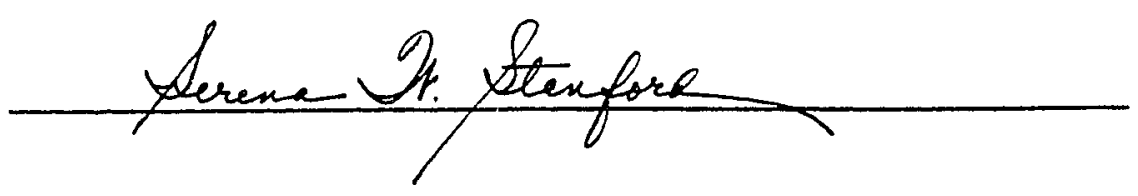




\section{ABSTRACT \\ THE PERCEPTION OF SIX WOMEN WITH DISABILITIES OF THEIR SELF-DIRECTED ROLE AS DANCER}

by Pamela Hope Dent, O.T.R.

This study uses naturalistic inquiry to describe occupational role acquisition of six women dancers who are physically disabled. Themes related to changes in occupational roles before, during and after onset of disability, focused particularly on self-actualization through the medium of dance and acquisition of the role as dancer are reported. Narratives illustrate rehabilitation experienced as a rite of passage in which the women entered a new culture and focused their identity as women, with disability.

Common themes that emerged were: honoring the process (of adapting to a physical disability), feeling "chosen" in the dancer role, finding an identity as a disabled person, identifying similarity to other minorities, identifying the need for a safe environment to explore physical abilities, recognizing the sense of loss as ever-present with a sense of joy in current physical activities, experiencing disillusionment with rehabilitation, and feeling good about the process of storytelling. Implications for occupational therapy theory and practice are discussed relative to story-telling and self-transcendence. 
Acknowledgements

I would like to thank Dr. Karen Diasio-Serrett for the inspiration for this study. She taught me to follow my bliss and listen to my heart, then follow that joumey wherever it took me, no matter how painful, or joyous, or chaotic it made me feel at the time. These emotions are just signals that one is living life and growing, transitioning to the next curve in the path of life! She has been so very patient with me.

I would also like to thank my friend, colleague, and soul-mate Thais Mazur for her collaborative efforts to allow me access to her unique dance company. Also, for her guidance in personal matters which have allowed me to keep my spirit alive, though barely at times. She has stayed close enough to give me the gentle "pushes" I needed at critical times.

I would also like to thank Dr. Lela Llorens for her professional guidance and scholarly example that 1 admire and respect. She provided balance and stability to keep me from going off on tangents and becoming too unrealistic, advice on research design and your personal understanding through my tough times. Also, to Alice Kibele, for being a patient and understanding reader.

Last, but not least, I'd like to thank my family for their patience and understanding in this long journey of research, especially my father who passed away during my research. He instilled in me the personal quest for self-transcendence while watching him fight a long battle with brain cancer. His resiliency matched the remarkable participants of this study. 


\section{Page}

Abstract

Acknowledgements iv

List of Figure viii

\section{Chapter 1 INTRODUCTION}

Purpose $\ldots \ldots \ldots \ldots \ldots \ldots \ldots \ldots \ldots \ldots \ldots \ldots \ldots$

Statement of the problem $\ldots \ldots \ldots \ldots \ldots \ldots \ldots \ldots \ldots$

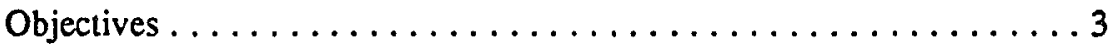

Questions ...........................4

Definitions . . . . . . . . . . . . . .

Assumptions $\ldots \ldots \ldots \ldots \ldots \ldots \ldots \ldots \ldots \ldots \ldots$

Limitations . . . . . . . . . . . . . . . . .

Significance of the study $\ldots \ldots \ldots \ldots \ldots \ldots \ldots \ldots \ldots$

\section{Chapter 2 REVIEW OF THE LITERATURE}

Women and Adversity $\ldots \ldots \ldots \ldots \ldots \ldots \ldots \ldots \ldots \ldots$

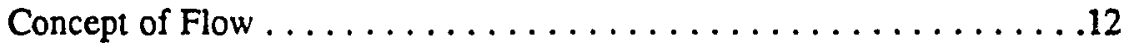

Concept of Resiliency . . . . . . . . . . . . . . . .14

Research in Occupational Therapy . . . . . . . . . . . 15

Conceptual Framework $\ldots \ldots \ldots \ldots \ldots \ldots \ldots \ldots \ldots$

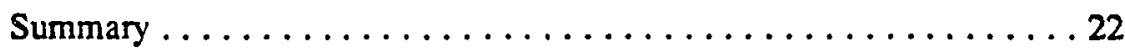

\section{Chapter 3 DESIGN AND METHODOLOGY}

Questions ............................ 33

Research Procedures/Methodology. . . . . . . . . . . . . . . 24 


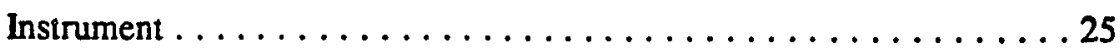

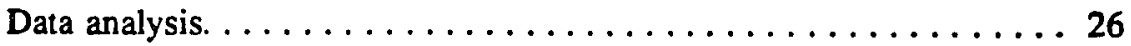

\section{Chapter 4 DATA}

Introduction to the participants $\ldots \ldots \ldots \ldots \ldots \ldots \ldots$

Abridged Life Stories of Six Paricipants . . . . . . . . . . . 29

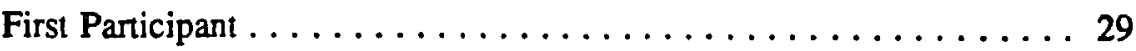

Second Participant . . . . . . . . . . . . . . . 33

Third Participant $\ldots \ldots \ldots \ldots \ldots \ldots \ldots \ldots \ldots \ldots \ldots \ldots$

Fourth Participant $\ldots \ldots \ldots \ldots \ldots \ldots \ldots \ldots \ldots \ldots \ldots \ldots$

Fifth Participant $\ldots \ldots \ldots \ldots \ldots \ldots \ldots \ldots \ldots \ldots \ldots \ldots \ldots$

Sixth Participant $\ldots \ldots \ldots \ldots \ldots \ldots \ldots \ldots \ldots \ldots \ldots \ldots \ldots$

Results ........................ 55

Question \#1a......................... 55

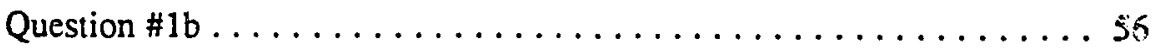

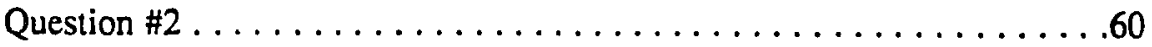

Question $\# 3 \ldots \ldots \ldots \ldots \ldots \ldots \ldots \ldots \ldots \ldots \ldots \ldots \ldots \ldots \ldots$

Question $\# 4 \ldots \ldots \ldots \ldots \ldots \ldots \ldots \ldots \ldots \ldots \ldots \ldots \ldots .6 . \ldots \ldots$

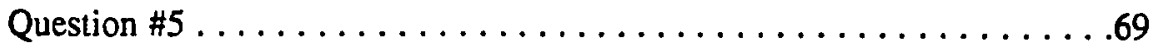

Question $\# 6 \ldots \ldots \ldots \ldots \ldots \ldots \ldots \ldots \ldots \ldots \ldots \ldots \ldots . \ldots \ldots$

\section{Chapter 5 COMMON THEMES}

Honoring the Process $\ldots \ldots \ldots \ldots \ldots \ldots \ldots \ldots \ldots \ldots$

Feeling "Chosen" in Dancer Role . . . . . . . . . . . . . . .76

Finding an Identity as a Disabled Person $\ldots \ldots \ldots \ldots \ldots \ldots 77$

Similarities to Other Minorities $\ldots \ldots \ldots \ldots \ldots \ldots \ldots \ldots$ 
Need for Safe Environment to Explore Physical Activities . . . 79

Sense of Loss Ever-present with Sense of Joy . . . . . . . . . .79

Disillusionment with Rehabilitation . . . . . . . . . . 80

Process of Story Telling Feeling Good and Therapeutic . . . . 81 Chapter 6 PROFESSIONAL IMPLICATIONS, RECOMMENDATIONS AND SUMMARY

Occupational Therapy Theory $\ldots \ldots \ldots \ldots \ldots \ldots \ldots \ldots . \ldots . \ldots 2$

Occupational Therapy Practice and Education . . . . . . . . .84

Occupational Therapy Research $\ldots \ldots \ldots \ldots \ldots \ldots$

Summary $\ldots \ldots \ldots \ldots \ldots \ldots \ldots \ldots \ldots \ldots \ldots . \ldots \ldots$

References ............................ 92

Appendices

A. Participant Informed Consent. . . . . . . . . . . . . 95

B. Letter to Physician . . . . . . . . . . . . . . . . 98

C. Physician's Confirmation of Diagnosis . . . . . . . . . . 100

D. Interview Guidelines . . . . . . . . . . . . . . . . . . 102

E. Sample "Mind Map" . . . . . . . . . . . . . . . . . . . . . 104 


\section{List of Figures}

Page

1. Representation of Model of Human Occupation 


\section{CHAPTER 1}

\section{INTRODUCTION}

\section{Purpose}

The purposes of this study were to (1) explore perceptions held by six women with disabilities regarding phenomena which have enabled them to engage in a self-actualizing, creative, playful activity and enter (or re-enter) into the occupational role of dancer in today's society and (2) to generate hypotheses for occupational therapists who practice with this population to "test out" new environmental and social support systems which might facilitate the "trying out" of new alternative or peripheral roles.

\section{Statement of the Problem}

In the last decade, occupational therapy literature has dealt with the growing science of occupation (Clark, 1993; Yerxa, 1987). In the physical disability rehabilitation clinic, however, the limited time allotted by third party reimbursers allows the practitioners only enough time to evaluate and treat the patient's occupational roles specific to routine "daily life tasks." As a result, once independence is achieved in self-care, home and community management and occasionally pre-vocational or vocational skills, they are discharged from therapy. 
Activities that utilize the body, as is, to bring joy and creativity to a person's life are not usually included in the plan of treatment repertoire. The optimal or peak experiences achieved in these kinds of activities are not associated with the routine nature of daily life activities, especially when these require extreme effort after surviving a catastrophic injury or illness. "Self-actualizing" occupational roles, such as dancer or artist (which bring about these peak experiences) are many times considered "peripheral" by occupational therapists in acute clinical settings and/or are referred to the recreational or dance therapist.

Occupational therapists play a major part in the transitional period during the rehabilitation phase. This stressful time requires changing habits, behaviors, attitudes and lifestyles/roles, which is seldom easy. This change or adaptation is necessary in order to achieve "success" or "competence" in new or adapted roles. Individuals who show resiliency in this process usually have an ability to find enjoyment and purpose in their activities regardless of the circumstances. This particular type of occupational behavior is best studied through the filter of a systems-based occupational therapy frame of reference. Consequently, environmental and social support systems needed to "try out" new alternative or "peripheral" roles will be more clearly identified for the profession. 


\section{Objectives}

This study sought to do the following:

1. Identify how lifestyle changes and stress brought on by disability change an individual's ability to engage in optimal or "self-actualizing" activities.

2. Identify participants' motivating factors which led them to choose dance as a worthwhile occupation in which to engage after their disability.

3. Identify factors which the participants attributed to allowing them to manage the role of a dancer.

4. Identify the experiences which enabled the participants to view themselves as competent/incompetent in the role of a dancer.

5. Identify conditions which foster reclaiming/development of "self-actualizing" occupational roles in addition to the traditional roles of self-care and community/work for the profession, especially by better understanding required social and environmental support systems.

6. Identify factors of which occupational therapists need to be aware to meet the needs of women who are physically disabled that relate to their clients' occupational role(s) regarding creative play/self-actualization. 


\section{Questions}

This study was designed to answer the following questions.

1.a) What did the participants do for optimal flow or self-actualizing activities as a child, before they became "disabled"?

1.b) How did lifestyle changes and stress brought on by the disability affect their ability to engage in optimal flow or self-actualizing activities?

2. What motivated the participants to choose dance as a worthwhile activity in which to engage after their "disability"?

3. How have the participants managed to reclaim or develop this positive, creative, use of their new bodies for a "total" engagement in a "flow" activity such as dance?

4. How do the participants view themselves in the occupational role of "dancer"?

5. Will the participants' recollections of any past occupational therapy reveal any attempts to address their occupational role(s) regarding creative play/self-actualization activities in either their treatment planning or discharge planning?

6. What do the participants believe health professionals (specifically occupational therapists) who work in rehabilitation settings should know regarding self-actualizing roles and other aspects of the rehabilitation process? 


\section{Definitions}

The following definitions were generated for this study:

Competency: The key to successful living; specific competency behaviors are guided by requirements of role(s). In acquiring competency behaviors one is able to have an impact on the environment. (Kielhofner, 1985)

Disability: Lack of competent power, strength, or physical or mental ability; incapacity.

Disabled: Restriction or lack of ability (resulting from impairment) to perform an activity in the manner or within the range considered normal for a human being. (World Health Organization, 1980)

Environment: Physical components are objects (materials of everyday life and their characteristics) and tasks/projects/activities that comprise play, work and self-care; Social components are social groups and organizations and culture.

Elow: The state in which people are so involved in an activity that nothing else seems to matter; the experience itself is so enjoyable that people will do it even at great cost, for the sheer sake of doing it. (Csikszentmihalyi, 1990) Habits: Routine behaviors which are performed during the day when an individual is not in a socially defined role. Kielhofner (1985) defined as images guiding routine and typical ways in which a person performs. Habituation subsystem: A collection of images which trigger and guide the performance of routine patterns of behavior. (Kielhofner, 1985) 
Interests: Dispositions to find occupations pleasurable.

Occupational Behavior: "This activity is goal directed, adaptive, organized, and named and classified by the culture within the ongoing stream of human activity." (Yerxa, 1987)

Occupational Roles: Include player, student, homemaker, worker and retiree, however, may have personal-sexual and familial-social dimensions. Kielhofner (1985) has stated a role is defined as having an occupational dimension if it provides an avenue for expression of play or leisure, or if it requires productive behavior. (p. 25)

Occupational Science: The "body of knowledge that is devoted to understanding the human being as one who engages in activity." (Yerxa, 1987, p. 417) Occupational Therapy: $A$ health and rehabilitation profession. Its practitioners provide services to individuals of all ages who have physical, developmental, emotional and social deficits, and, because of these conditions, need specialized assistance in learning skills to enable them to lead independent, productive and satisfying lives. (A.O.T.A., 1990) Optimal or peak experiences: Occur when a person's body or mind is stretched to its limits in a voluntary effort to accomplish something difficult and worthwhile. In the long run, add up to a sense of mastery- or of "participation" in determining the content of life, or "happiness." Personal Causation: Refers to an individual's personal knowledge of self as a cause who creates observable changes in the environment. 
Performance subsystem: A collection of images and biological structures and processes which are organized into skills and used in the production of purposeful behavior. (Kielhofner, 1985)

Resiliency: Process of getting back strength, spirits, etc., quickly; buoyant (Webster, 1971). Csikszentmihalyi (1990) stated that those who possess it have the ability to take misfortune and make something good come of it. Roles: Positions in social groups in which persons are expected to behave a certain way because of their status. When a role is internalized it becomes part of one's self image and serves as a source of identity. (Kielhofner, 1985) Self-actualizing activities: Maslow (1968) coined this term referring to reaching human potential, that after more basic needs are satisfied, goals may begin to be effective in directing actions. By involving themselves in these type of activities, people feel at peak with their powers, and selffulfilled, natural, free-flowing, creative and uninhibited. System: A set of objects with interrelationships that allow them to function collectively toward an identifiable purpose.

Values: Images of what is good, right or important; principles which guide human conduct.

Yolitional subsystem: Interrelated set of energizing and symbolic components which together determine conscious choices for occupational behavior. (Kielhofner, 1985) 
Assumptions

In proposing this study, the researcher made several assumptions:

1. The study sample will have sufficient memory and communication

skills to relate both objective and subjective life experiences.

2. By interviewing each participant, information regarding the participants'

lives and concerns and values which are meaningful in their daily lives will

be candidly and honestly discussed.

3. The participants, who are adults and live independently in the

community, are capable and willing to talk about services they

have received from medical and rehabilitation providers.

4. The participants, who have all been, or currently are members of a professional dance company and have all had experience performing dance in front of a paying audience, have demonstrated an ability to participate in creative, "flow," or self-actualizing activities by this experience.

5. The participants represent a sample of resilient individuals as evidenced by their persistent efforts to overcome the adversity in their lives as demonstrated by their life stories. 


\section{Limitations}

Limitations have been identified as follows:

1. There is no generalizability of the findings to other women with physical disabilities due to the uniqueness of the sample. Even if a similar population could be found, matched for age, diagnosis and background who were also dancing, circumstances regarding the narrow range of environments ("liberal" in Berkeley/San Francisco/Cleveland) could not be accounted for. The cultures in these cities may not be representative of other cities in the U.S.A.

2. There could be a possible bias due to prior friendship with the artistic director and the researcher; however, all efforts were made to put that aside, and the artistic director was not, in any way, a part of the study or had access to the data.

3. The researcher has had a past history with dance, which brings with it bias regarding perceptions'; however, care was taken to make sure all interviews were carried out in an objective manner. This experience should only add to the enthusiasm of the study due to the love this researcher has for this occupation.

4. Any possible bias regarding the researcher's prior knowledge of some of the participants would be offset by the participants' increased comfort with the interviewer. Inclusion of other participants not previously known to the researcher could also offset the possibility of bias. 
Significance of the Study

This study expected to show that women with physical disabilities can provide valuable information regarding their process of engaging in playful, creative and self-actualizing occupational behavior (specifically dance). Results are expected to be used to understand clients with physical disability who wish to make extended, self-determined choices in occupational behaviors during both the acute rehabilitation phase, and in the home/community reintegration phase.

As a result, this understanding might help to facilitate this population to engage in self-actualizing activities utilizing the body to find enjoyment and purpose regardless of external circumstances or adversity. Without their creative or self-actualizing needs being met, clients may not realize their fullest potentials for self-actualization, even though they are "functional" and/or "contributing" members of society. 


\section{CHAPTER 2}

\section{REVIEW OF THE LITERATURE}

The literature review is divided into four areas of focus. First, it includes a discussion of women and their perspective on adversity in life experiences. Second, concepts of optimal flow or creative ("self-actualizing") activities and resiliency are discussed. The significance of humans engaging in dance or "flow" experiences, even under adverse circumstances, is presented. Third, a review of similar case studies is made from the occupational therapy literature on the self-perception of individuals' life experiences with physical disabilities and their implications for occupational therapy. Fourth, and finally, the conceptual framework of this research, including the rationale for choosing a systems-based frame of reference from the occupational therapy profession, called "Model of Human Occupation," will be presented.

\section{Women and Adversity}

Women, especially those with a physical disability, are often caught between conforming to existing standards or role definitions which society (or the local culture) dictates and exploring the promise of new alternatives. Bateson (1990) studied the life histories of five of her ablebodied "intellectual" women friends in her book "Composing a Life." 
She set a number of life histories side by side, and recognized common patterns of creativity that had not been acknowledged or fostered previously. A woman often feels out in the margins of society and encounters discontinuity when her life's roles do not develop "as expected." Bateson argued that diversity, adversity, disorder and crises can be turning points for growth. She also stated that:

An encounter with other cultures can lead to openness only if you can suspend the assumption of superiority, not seeking new worlds to conquer, but new worlds to respect. (p. 66)

This is especially true when people end up in a new culture against their will by becoming disabled. Therefore, it is important to look at people's selfperception regarding their involvement with the creative roles in society, in addition to people's self-perception regarding the new culture and/or environment with which they are interacting.

\section{Concept of Flow}

Csikszentmihalyi (1990) developed his theory of optimal flow because he wanted to know what enabled some people, despite hardship and difficulties, to stand up and enjoy a serene life. These people were often an inspiration to others. Over the years Dr. Csikszentmihalyi noticed a correlation between creativity and happiness. Optimal flow considers the relationship between leisure (active leisure vs. passive leisure), work, and life maintenance activities in respect to the pleasure and satisfaction they bring. People are in a state of flow when their personal capabilities match the challenge of tasks set before them. Flow is all self-perception. When in flow, the person loses track of time; he or she gains a clarity of goals and 
feedback; there is a feeling of being in control. It is a "success" experience, characterized by self-confidence and satisfaction. Anxiety could be considered the antithesis of flow because it is characterized by a personal perception that one does not have the skills to meet the challenge at hand.

Kibele (1986) found that all five of the participants with disabilities in her study described having experienced the sense of "flow" while engaged in meaningful activity which included work and leisure tasks (such as total involvement in a community meeting, teaching, creative writing, gardening, swimming, dancing, painting, communicating with a valued friend and lovemaking). These adult participants with cerebral palsy described being less aware of and able to transcend the limitations of their physical bodies, which do not typically serve them well, even while involved in tasks thought to require motor skill they perceived as lacking. The participants reported feeling satisfied with their performance to such an extent that lack of coordination was devalued.

Yerxa (1987) recommended that the occupational therapy profession attempt to study how the continuum of occupation with its roots in childhood play leads to competence and achievement behavior in the adult and to well being, fulfillment, and life satisfaction in the older person. She has discussed the need for the profession to reclaim the essence of it's roots in human occupation in creative play. Clark (1993) related the creative play activities in which her respondent participated as a child to her coping strategies utilized as an adult after the onset of disability (i.e. her writing and storytelling skills). This was the respondent's way of nurturing her human spirit to act (Reilly, 1962), or what this author would consider 
"resiliency." This was the occupational behavior which she could carry into her real life after her disability and help to make sense of it all. The respondent's participation in the writing and story telling also appears to fit into the category of a optimal flow activity.

\section{Concept of Resiliency}

Fine (1991) posed the question "Who rises above adversity, and how?" in her 1990 Eleanor Clarke Slagle Lecture. She pursued many life narratives in an effort to more fully understand factors that influence resilient responses. She stated the most valuable data came directly from the personal experiences of those struggling with the sequelae of disease or illness or the aftermath of natural or manmade disasters.

Fine (1991) stated it is not so much what happens to people but how they interpret and explain it that makes a difference. Resilience appears to be less an enduring characteristic and more a process determined by the impact of a particular life experiences on particular conceptions of one's life history. The factors which influence human capacities to shrink, hibernate, and flourish under extreme stress are personal perspective and the people, places and things in the environment. Fine believes that

Occupational therapists are far more effective at defining reality and assessing and promoting performance then we are at assessing and making use of patients' views of themselves and their situation. Although some therapists appear to use such information and their relationship in treatment, their ambivalence about acknowledging it relegates it to an underground practice and reflects troublesome conflicts in values. We must remind ourselves that psychosocial phenomena belong to everyone, irrespective of their diagnosis and health status. Practice that separates feelings from function and psychosocial from physical perpetuates disorder rather than fostering reintegration. (p. 501) 
Through active listening to our clients telling their life stories health professionals can learn about the process of resiliency. Capra (1982) views humans as self-organizing systems with ability for self-healing and adaptation (self-renewal), and also the ability to reach out creatively beyond physical and mental boundaries in the process of learning, development and evolution (self-transformation and self-transcendence).

\section{Research in Occupational Therapy}

Some studies in the occupational therapy literature were found which analyzed the perspectives of individuals with physical disabilities on their occupational behavior. Three occupational therapists who conducted qualitative research studied different populations (i.e., diagnoses of rheumatoid arthritis, cerebral palsy, and cerebral vascular accident respectively) found similar common themes (Clark, 1993; Kibele, 1986; Schumacher-Davis, 1991).

Kibele (1986) and Schumacher-Davis (1991) both reported that "control over one's life" and attitude of self as most important factors which affect clients' lives. This includes the ability to make all of the important decisions which affect the quality of their lives, or having a "free will." A persistent and self-disciplined, yet accepting attitude is also important. The attitude of people with whom they deal on a daily basis included the ability for others to see the participants as persons first, rather than perceive them as synonymous with their disability, especially when dealing with the uninformed public. 
Kibele (1986) also found that her participants perceived that it was empowering to immerse themselves in a peer culture of disabled persons as opposed to the disempowering experiences the participants felt while in the rehabilitation process. They encountered the independent living movement after being discharged from therapy services. In the independent living movement culture, they received advice and help from disabled peers who had been through the process of making it to independent living status and who shared the good feeling which they experienced when they were in control of their lives again.

Clark, in her Eleanor Clarke Slagle lecture (1993), described the occupational behavior and self-perception of a woman suffering from a cerebral vascular accident via an in-depth life story interview. Her participant also described the same perspective about rehabilitation and called it her "rite of passage." She felt that she was moved to disability status by the therapist, then abandoned. In all three studies, in the rehabilitation setting, participants felt that only their dysfunction was seen. These participants expressed that the relatively narrow focus of medical treatment and therapy goals had the effect of protecting them and isolating them from real world experiences. A subtle perception of false hope that the participants had regarding being "fixed" of their status of being disabled was placed in the rehabilitation professional expert status. When the goals of independence in activities of daily living and ambulation were not met at discharge, the participants felt like failures, "let down" and disillusioned. The participants also felt that the energy, or "urge" that each person has to explore and master the skills needed for their occupations was 
sometimes "used up" on unsatisfying occupational choices. The ability for self-control after being labeled disabled and being immersed into a new and different culture is like finding yourself in a minority group, but with no tools with which to cope. In addition, loss of previous social support systems added to the major variables affecting their lives.

The implications for occupational therapy included viewing the client in a larger perspective. As Kibele (1986) stated "By attending only to norm-defined functional skills, therapists may miss the relative value of those skills in the lives of clients/consumers" (p.128). Results of her study confirm that occupational therapy must incorporate a systems approach to assessment and treatment.

\section{Conceptual Framework}

The researcher chose to use a systems conceptual frame of reference to examine the self-perceived images of the disabled women of this study. This choice was made to better grasp the common themes among how the women viewed their disabling condition, their self-directed occupational behavior and roles, their culture and their ways of composing their lives.

Because of the complexity in acquiring this information, a systems-based theoretical framework was utilized with emphasis on seeing the "whole" picture with as many interconnections as possible. From a systems perspective, the human is assumed to be a self-organizing system which means that its order in structure and function is not imposed by the 
environment but is established by the system itself. Self-organization has two principal dynamic phenomena: self-renewal and self-transcendence (Capra, 1982). The self-transcendence level explains people's desires or urge for seeking creativity. The self-renewal, or maintenance level has been viewed traditionally in occupational therapy literature as the ability to care for oneself. However, for the purpose of this study, occupational behavior will be studied as it applies to self-transcendence. The concepts of optimal flow and resiliency will be incorporated because, in the author's opinion, they assist to explain how human beings reach these self-restorative and self-transcendence levels.

Rogers (1984) suggested studying occupation through the filter or perspective of occupational therapy philosophy. In the occupational therapy literature, the closest conceptual framework this author could find which somewhat approximated the levels of human functioning in a systems context was the Model of Human Occupation. Kielhofner, et al., (1985) described a systems-oriented frame of reference associated with studying the processing of occupational behavior of humans. It was based on occupational behavior theory that was first advanced by Reilly and expanded by others (Yerxa, 1983). A visual explanation of the model is that constant environmental (objects, tasks, etc.), societal and cultural stimuli via input, throughput, output and feedback is filtered through the different levels of the human. (See Figure 1) 
Figure 1

Representation of Model of Human Occupation

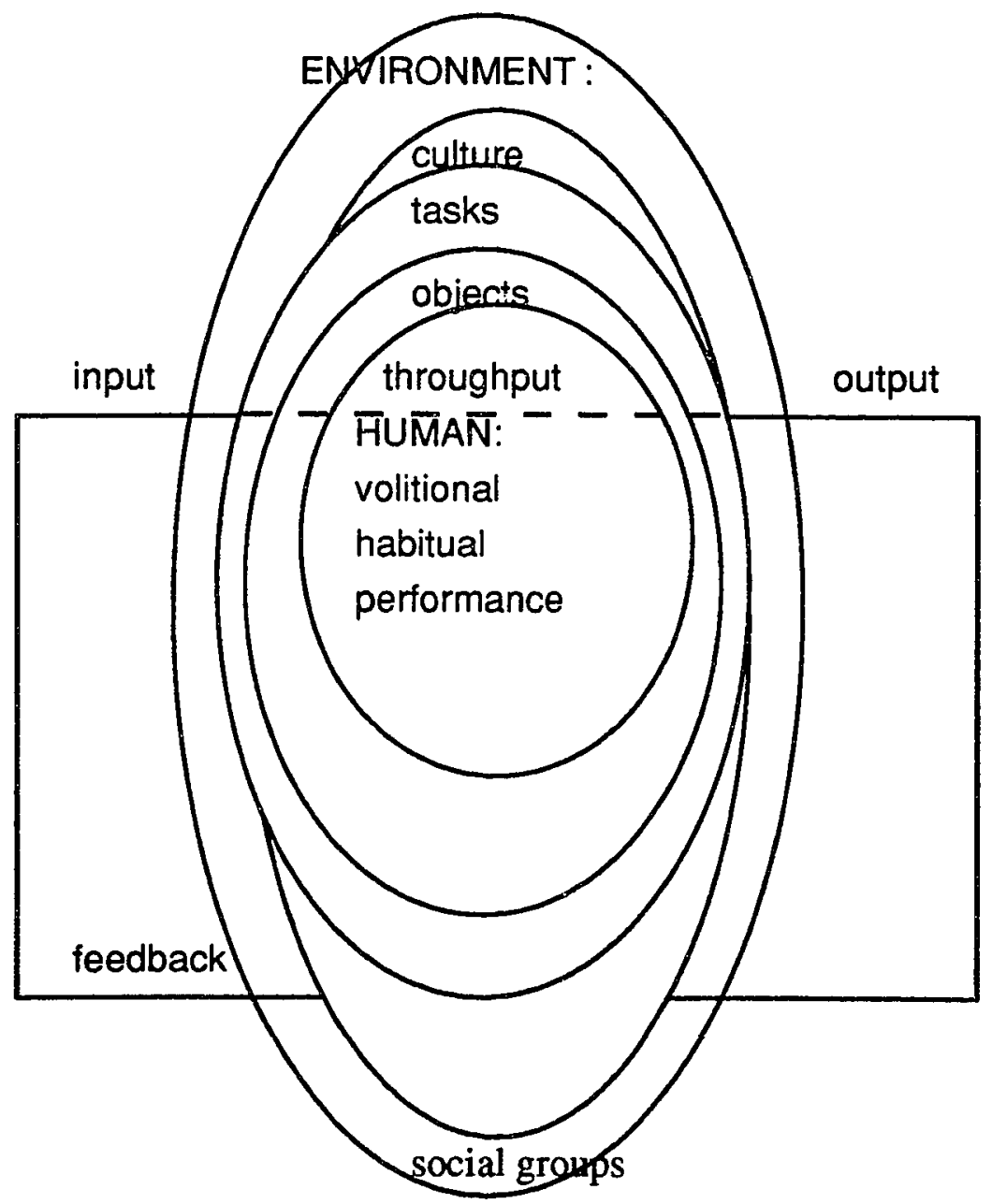


In this model, these levels are interpreted as the human having its own hierarchy of subsystems which are volition, habituation, and performance.

Within the subsystems, personal causation, values, interests, roles, habits, skills and their musculoskeletal, neurological and symbolical constituents of skills are identified as important dimensions of occupational behavior. These subsystems attempt to explain how occupational behavior is motivated, organized and performed and they work together in an integrated fashion, along with the environment. This allows the human system to output occupational behavior which is represented by a continuum from automatic performance of routine everyday behavior to the conscious choices for occupational roles.

The information on the volitional subsystem has provided a structure that clarifies and defines a person's self-perception of their ability to function in the self-restorative and self-transcendence level. Fine (1991) believes that the phenomena of affective and cognitive processes are often ignored in the clinical reasoning and practice of many health professionals. Fine stated:

The voices of the resilient send a powerful message: Personal perception and responses to stressful life events are crucial elements of survival, recovery, and rehabilitation, often transcending the reality of the situation or the interventions of others. The inner life...holds the potential for transforming traumas into varying degrees of triumph. (p. 493)

The components of the volitional subsystem in the Model of Human Occupation addresses some of the cognitive processes, but it is questionable whether it accounts for the affective processes of a person's self-perception regarding their life experiences and meaning of occupational activities. 
The environment includes both the physical and social components which include opportunities to practice new roles.

Environments in which the opportunity to engage in occupation is restricted may have a negative influence on performance, and the individual might not have a means of demonstrating and realizing their potential, or "self-actualize" (Rogers, 1984). Occupational therapists assist individuals to identify and select occupations/activities which will facilitate persons in maintaining and changing their function both in the environment of the occupational therapy clinics and in the person's home and community settings. Restrictions in opportunities to engage in the full spectrum of occupational activities and roles occur daily in the lives of physically disabled persons. This author believes the occupational therapist can most readily assess for the existence of restrictions, identify the physical, emotional, cognitive, environmental components, and the person's strengths in dealing with adversity.

Meyer (1922) identified central concepts of occupational therapy, focusing on the value of work and play as the primary activities occupying human time, interest and energy. After reviewing the above literature, this author poses two questions:

(1) If occupational therapy practice choices are always self-care and productivity, where is the balance of the profession's core concerns?

(2) Does the occupational therapy profession risk a loss of identity and balance in its scope of practice regarding occupational roles and activities which are truly meaningful to clients? 
Reilly (1962), Yerxa (1983) and Clark (1993) have posed similar questions in the literature which pioneered the occupational science movement.

\section{Summary}

In summary, the occupational therapy literature revealed the need for more research on the self-perception of the human efforts to not only maintain self and contribute productively to society, but to participate in the playful and self-actualizing events of the culture. Included in this information is the perceived environmental and social support systems, which enhances or limits the desire and ability of the individual's performance in participating in selected occupations. This information will best be defined by utilizing a systems conceptual model. Information will be sought utilizing the parameters from the literature that include resiliency, flow and self-transcendence. The overall direction this author perceived from the literature was a need to further clarify the selfperceived importance creative or self-actualizing roles play in the process of development of a resilient nature in the lives of our clients. 


\section{CHAPTER 3}

\section{DESIGN AND METHODOLOGY}

The scarcity of prior research on this topic with this population has prompted a naturalistic, qualitative design utilizing case study methodology. DePoy and Gitlin (1994) describe life history design as naturalistic because of its focus on individuals' lives in the context of the social environment. In this research, the investigator looks primarily to the informant, not only to produce the data, but also to provide analysis of their meaning. This design lends itself to also looking at the life process transversed over time. Data were collected by individual, in-depth interviews. The interviews were structured based on a systems perspective and aimed at discovering recurrent themes via content analysis. Participants were asked to focus on the essence of their life histories regarding the process of the development of their creative or self-actualizing roles (especially related to dancer role).

\section{Questions}

This study was designed to answer the following questions related to the objectives previously discussed.

1a) What did the participants do for optimal or self-actualizing activities as a child, before they became "disabled" ?

1b) How did lifestyle changes and stress brought on by the disability affect their ability to engage in optimal flow or self-actualizing activities? 
2. What motivated the participants to choose dance as a worthwhile activity in which to engage after their "disability"?

3. How have the participants managed to reclaim or develop this positive, creative, use of their new bodies for a "total" engagement in a "flow" activity such as dance?

4. How do the participants view themselves in the occupational role of "dancer"?

5. Will the participants' recollections of any past occupational therapy reveal any attempts to address their occupational role(s) regarding creative play/self-actualization activities in either their treatment planning or discharge planning?

6. What do the participants believe health professionals (specifically occupational therapists) who work in rehabilitation settings should know regarding self-actualizing roles and other aspects of the rehabilitation process?

\section{Research Procedures/Methodology}

This study was designed to look at unique aspects of occupational behavior among adult females who were born with or have acquired a physical disability and who have integrated into the dancer role. The "convenience" sample was taken from various "disabled" Dance Troupes based in the San Francisco Bay and Cleveland areas. No control was placed on the iypes of physical disability diagnoses; however, all diagnoses were verified by a physician. A minimum of six subjects was set. The subjects 
were members of dance troupes. Six volunteers were invited to participate as subjects.

Previous to this study, the researcher had met two of the subjects and had brief introductions through a mutual friend who is an artistic director of one of the dance troupes. This mutual friend provided the investigator with the names and telephone numbers of the participants after asking them if they were interested in being potential respondents in this study.

The procedure for each interview began with an initial contact by the investigator via telephone to confirm the participant's interest and arrange a mutually agreed upon time and place to meet. Following a brief introduction period to establish rapport with the participant, the consent form (Appendix A) was introduced and signed. Study goals, including intentions to publish, were reviewed with the participants. To insure the validity to the diagnoses, a form was also signed by the participants which allowed the researcher to send a letter to their physician (Appendix B) to secure confirmation of diagnosis (Appendix C).

\section{Instrument}

Interview guidelines (Appendix D) written by the researcher were utilized in order to collect specific information pertinent to this study. The researcher did not attempt to maintain rigid control of the interview and encouraged flexibility when participants felt information was relevant. Interviews were tape recorded on a audiocassette and transcribed. Data were seen by the researcher only and have been kept safely in the privacy 
of the researcher's home in a locked file cabinet. Following final approval of this study, all the confidential data given by the respondents will be destroyed.

\section{Data Analysis}

The first stage of data analysis began with data collection. According to DePoy and Gitlin (1994), ongoing analysis occurs immediately as one enters the field. Data were gathered by means of in-depth interviews lasting from two to four hours. The interviews took place at the location of the participant's choice. These interviews were tape recorded with permission. Initially, demographic information was compiled and physician verifications of diagnosis were procured. Notes were also taken during the interview by the researcher which identified important parts of the interview to cue the researcher to go back to when reviewing the transcripts, especially if the participant stressed the importance or value of the data. This facilitated the inductive reasoning process which DePoy and Gitlin (1994) have described when the investigator continually strives to place each piece of data into a context to understand the bigger picture or how parts fit together to make the whole. This "contextualization" is one of the first meaningful ways in which to begin organizing information in which to develop categories.

In preparing the data, interviews were first reviewed on tape for intelligibility and timed. Then they were transcribed on a word processor and sent to the participants to check for accuracy. The participants were 
given the opportunity at that time to edit out any sensitive content they wanted or did not wish to have in the published version. This helped to ensure some of the participants' confidentiality.

After the transcriptions were returned by the participants, the researcher re-read the transcripts, underlining the comments which were meaningful in context to the question asked, which is called contextualization. This was the beginning of stage two, or what DePoy and Gitlin (1994) call formal analysis. Comments were then collected from the transcription utilizing a "mind map" (Diasio Serrett, 1987, p. 84) for each question (See Appendix E). Common themes were then visually identified (categories) by assessing which comments were most common to all of the respondents.

Common themes were then written across the top of a story board and index cards with comments and longer quotes were placed under each common theme category which best described or illustrated that theme for the summary (Kibele, 1985). The discovery and revelation of the participants' perspectives regarding the meaning they have assigned to their dancer role could then be reported. 


\section{CHAPTER 4}

\section{DATA}

Data were collected through in-depth interviews conducted between April 4, 1993 and February 10, 1994. Scheduling of the interview sessions were based on the mutual availability of participants and the researcher. Each interview session lasted from a minimum of two hours and up to four hours. Four of the interviews were conducted in the participants' homes, one was conducted at a hotel, and another at the dance studio where a class was being held on that day.

There were a total of nine interview sessions for all six participants; two sessions, two hours each for each of the first three participants; and three two hour sessions for the last three participants. The average time for each interview was three hours. Total time spent in interviews was 18 hours (tape-recorded time). Additional time was spent informally in the rapport-developing phase, which amounted to approximately one additional hour for each participant.

Participants varied in their openness of communication and trust levels as might be expected; however, one participant was particularly leery to speak openly because of a bad experience she had which was directly related to the subject matter.

\section{Introduction to Participants}

The participants were six adult women with physical disabilities who are dancers. They all live independently (some with partial attendant care) 
in urban and suburban neighborhoods of Alameda County, California and Lake County, Ohio. These women ranged in age from $34-38$ years old. They classified themselves as being from a middle class socioeconomic background. Four stated they were single and two stated they were married. Three of the participants acquired their disability as teenagers and one as an young adult. One acquired a disability at 18 months old, and one was born with a disability.

\section{Abridged Life Stories of Six Participants}

The following stories are told from the perspective of each client and attempts to utilize their words as much as possible:

\section{First Participant}

Participant Number One is a white 34 year old woman who lives in a bottom floor condominium in Oakland which is completely wheelchair accessible. She has a quaint little garden in her side yard which she tends and loves. According to her doctor, she has been diagnosed as "Quadriplegic." She lives independently with part-time attendant care from a live-in friend. She supports herself financially with Social Security Supplemental Income (S.S.I.) payments, although she works nearly full-time as the administrator for her dance troupe. She has had some college background, but did not finish her degree. She has been disabled for half her life, 16.5 years.

Her story begins where she was born in Colorado. She grew up in rural areas and loved the out of doors. Her favorite activities were riding and being 
with horses, gardening, and nature. She preferred animals more than friends. She was given her first horse when she was 9 years old, and, to her, it felt like 150 years had passed. At 12 years old she started competing in the hunters and jumpers circuit, and within a few years was the Colorado state champion in jumping. She was "bored" with school and did what she had to do to get As. She described most of these childhood activities as goal oriented and not process oriented. She was pushed to progress and develop discipline by a friend of the family who also provided the financial support for these activities. She described the whole experience as a "mixed bag"; "it really gave me something I could be incredibly passionate about and devote my life to," but "it was wrapped up with a lot of [emotional] pain." The friend was attempting to dominate her. Any positive reinforcement was conditional on how good she was doing.

She started drinking as a teenager as she needed an outlet to rebel, decrease the pressure and expectations, and be her own person. Unfortunately, this period ended when she "got hurt." She was driving a van on a winter night while drunk and was thrown through the windshield, "breaking her neck." This was Dec. 9, 1977 and she was 17 years old, a senior in high school. She had enough credits completed to graduate, so did so without returning to high school.

While in rehabilitation, her mother, the identified caretaker, started drinking heavily and her horse died. Her peers and friends from the horse world were there to support her. She went home with her mother, who was on "overwhelm," and she reported that her mother tried to commit suicide one 
morning while in a drunken stupor for hours. Her mother would not respond to the participant's calling out from her bed. Watching these events scared her and she decided never to get that depressed. She had a fear of being stuck in bed due to being dependent for transfer mobility.

She went into business with the friend who financially supported her all along. They leased a ranch and taught students to jump and show horses for the following six months. She described feeling pitiful, but it was in her "niche" (or culture). An attendant from the rehabilitation center moved in with her at the ranch. This set-up fell apart due to the friend's dominance once again, and her attendant walked out on her. She ended up moving back in with her mother for two years which she described as "hell." Her mother was dying from cancer and was on chemotherapy, yet was still irying to be her attendant. This was the lowest point of her life. She had no friends for support, even in the horse world culture.

The participant's sister studied the situation and decided it was time for the participant to move to an independent living center. The participant felt like she had no choice in the matter, but didn't have other solutions. She then found herself living in Boulder, in the city for the first time, with no friends. Attendants were lined up for her and she prepared to start college. Of course, business classes were recommended by the vocational rehabilitation counselor. She moved there in April, 1981 and her mother died July 1, 1991.

She attributes the self-discipline that she developed with the horses to making it through that period. She was "forced" (out of necessity) to go out into public to go shopping for her food and other items. She started developing friends in the disabled students program and began learning about the 
"resources" available, despite having a lot of trouble being around other disabled people. (She didn't want to "see that reflection"). She had not, at that point, let go of the old identity with the horses. In winter of 1982 she was asked to be on the original advisory board for therapeutic riding in Denver, CO.. She explained this time as "hanging on to that little thread of identity" with the horses: "It was who I was."

Then came the turning point, she awoke in the middle of the night one night and something told her she needed a change. She decided to move to California, lived in Berkeley through the advice of a friend, and "posed" to be attending University of California. She had no intention of going there for college. She explained her first day in Berkeley as:

So, I ended up in Berkeley, CA. and there are so fucking many crippled people around here that I was sure the first day I was here that there had to be a convention somewhere. I hadn't seen that many disabled people since I had gotten out of rehab.

She then became "very involved with the disabled community, especially the students at Cal." She dropped out of school and did volunteer work for the World Institute on Disability and Center for Independent Living Office. She ran around, made friends and partied or drank a lot. Moving to Berkeley felt crazy to her and she bounced around from one activity to another from 1983 to 1987.

She then started booking events for the Women's Philharmonic and realized she had a knack for working with people. Some of her friends invited her to take a women's self-defense class, go swimming, and do "bodywork." This is where she met the artistic director of the dance troupe and was asked to join. Before this, she could not find anything; "I feel like it took me ten years, up 
until the time I started doing martial arts and dance. I felt like I spent ten years trying to get my life back together, and trying to find something that would fill the place of the horses in my life, and something I could feel good about, and that 1 could feel good about myself in." She was excited because it had great potential for a physical outlet.

At first, she felt like she had four left wheels, and the movements were hard to remember, but she was in her first performance three months later. She stated, "Once you hear the applause, you're sunk." She got really hooked after each consecutive dance and performance as they were all "hits." She quit booking events for the Women's Philharmonic and began writing grants and helped the dance troupe to achieve non-profit status, thereby slipping into an administrator role. At the same time, she was increasing her assertiveness and decreasing her passivity, her whole life began to blossom and things within her began to emerge. It was a matter of being in the right place at the right time. She also attributes this change to beginning Zen meditation.

\section{Second Participant}

Participant Number Two is a 36 year old Caucasian woman who is married to a man with a physical disability. They live in a single story wheelchair accessible dwelling in Berkeley, CA. Her physician has verified her diagnosis as quadriplegia. She earns a living as a travel agent, specializing in travel for the disabled. She received a bachelor's degree from Chico State University in Therapeutic Recreation. Twenty one years have passed since the onset of her disability. She identifies herself as having a Jewish father and parents who are committed to civic service and that "they are very giving." 
Her story began in Michigan where she grew up as a child and was very active in physically-oriented activities such as dance, sports and other outdoor activities. She was called a "tomboy." These activities came very easy to her and she really enjoyed them. She also liked to play music and sing. Dancing was very important in her life and it gave her pleasure to be "in her body and not in her head." She was involved in civic group activities. She talked about being Jewish and listening to her dad's stories about internment in Auschwitz and how that affected her. She dreamed about living off the land in a kibbutz.

After just turning 15 years old, Participant Number Two was in an accident and broke her neck. She attended rehabilitation, although when asked, she tells people she had no rehabilitation because of the lack of value she received. At that point her life changed drastically. She could not see being able to do anything that she enjoyed doing before, which she attributes partly to a lack of awareness. She even struggled to find an instrument she could play, but to no satisfaction. There occurred this "degree of impossibility" regarding her perceived ability to ever experience joy or satisfaction while attempting to participate in a physical and/or creative activity. She felt as if this would last forever, but that it varied from day to day. For the first few years she thought about this impossible situation a lot, and became depressed. Her internal dialogue included statements such as: "This sucks." "This is really depressing sitting in a wheelchair and not being able to be physical." She finished high school as the only disabled student, but was able to stay in contact with her friends. Then she went away to college, feeling at that point that she had no other options. She told her parents that she had to get out of the cold climate, because the snow really interfered with her mobility. 
She chose a college in Redlands, CA because it had an independent study program in nutrition. The college turned out to be inaccessible and she hit the all time low point in her life while there. All of her friends would try to include her in their activities, but she would still find herself feeling very lonely and isolated while they would all go off for a ski weekend, for example. She became severely depressed and was the time period in her life when "it" finally started to hit her, "That life I'm living." She became physically ill and contemplated suicide.

She ended up being admitted into a hospital in Michigan...and it was there, that things really started to turn around for her. She was re-admitted into the rehabilitation unit after a few weeks in the hospital. The entire rehabilitation team was amazed at how independent she had become, and raved about her. She was a quad, at her level, living on her own, and performing her personal care independently. This was something they had never seen, and that they told her she would never achieve when she was in rehabilitation the first time. This experience really put things into perspective for her. She realized that she had actually accomplished a lot. She returned to California with a different perspective. She realized that she wanted to leave Redlands, $\mathrm{CA}$ and find somewhere that was less smoggy and more accommodating to "disability."

After that, she and a close friend decided to "take off." She was feeling better about herself because she started focusing on what she could do instead of what she could not do. These "hippies" drove around "looking for somewhere to land" for six months. They ended up in Santa Rosa, CA. It was 
here that she discovered the adapted physical education program at the junior college. Her "degree of impossibility" began to change after she started making connections with other students with disabilities and learning from them how to unleash her own possibilities. She found that she had not reached her full potential. Her mobility and strength improved through a fitness program of swimming and weight lifting. Within a year she enrolled in the new competitive sports program. The process of getting to that point and the camaraderie were enjoyable. She was able to travel, and described being around a group of 500 other people with disabilities as "very empowering." She defined freedom in the environment as being "if your leg starts to spasm, you just let it spasm." She talked with people and learned a lot of the tricks she did not learn in "rehab." She spent less time dwelling on what she could no longer do. It was a matter of achieving an identity, moving from not really knowing what she could do or be as a person with disability to having a place to belong.

Soon she started participating in outdoor adventure activities such as rafting and kayaking, and became involved with a group called environmental traveling companions (E.T.C.). About that time she received a settlement from the accident and bought a farm in Sebastapol, near Santa Rosa. She stated "I actualized this dream of having a farm and it was extremely frustrating because I could not set it up so that I could do all the work." She loved living there for ten years, but hated going up and down the 60 foot ramp she had built in order to access the house. A friend, Carol, lived there until Participant Number Two's first boyfriend moved in. When he moved out after about two years, she enrolled in Sonoma University.

She finished her B.A. degree in Recreational Therapy at Chico State 
University and performed her internship at Bay Area Outreach Recreational Programs (B.O.R.P.). This was a nonprofit agency in Berkeley, CA. She ended up relocating to Berkeley and always remarked, "My heart is in the country, but my body is in the city." After a while of struggling, she finally sold her farm. She met her second love in Berkeley who was a person with a background in theater arts.

While working at B.O.R.P., Participant Number Two received a phone call from a friend who was in the dance troupe (where she is now a member). She was asked to dance with them without the friend even knowing she had danced for ten years of her life. She had to make a decision in twenty-four hours. She really "stressed out" over the decision, but decided to take the risk. She figured "What have I got to lose?." Within six months she was dancing the star role in front of an audience of over a thousand paying people, although she did not feel $100 \%$ safe being in front of an audience as a disabled person, at this point.

She described many terrifying moments. When questioned why she stayed in it, she replied that it was the process, more than the end result. Although there is a real high that occurs when the performance is finished, and everyone is clapping; however, it is still the process. She describes the process as basically like a family.

Currently, she feels more comfortable on stage where people are allowed to look at her versus out on the street where she remains aware of people looking at her. She stated "it's like saying here I am, like it or not, this is what I have to offer. The dance floor is a safe and accepting environment, whereas, out in the real world it is not, it is sometimes a total alienating environment." 


\section{Third Participant}

Participant Number Three is a Caucasian 35 year old woman who is single and lives in a downstairs apartment in Berkeley, CA. Her physician verified her diagnosis as progressive facial scapular peronial muscular dystrophy, a condition which she has had for 17 years. She earns a living as a medical social worker on an AIDs unit. She received her master's degree from University of California, Berkeley after receiving a bachelor degree in Psychology from Lewis and Clark University.

Her story begins with her growing up in Santa Rosa and a love for any activities. Her concept of herself was as an athlete. She also loved to camp, swim and dance. At age 7 , she started swimming competitively. She especially loved this activity because she loved the feeling of being totally streamlined in the water. She had an image of slicing through the water without making a sound and being totally buoyant. She also joined the synchronized swim team. She always loved to dance and pretended that she was Ginger Rogers floating around the dance floor with Fred Astaire while she was taking a couple of years of ballroom dancing. She also was in gymnastics and very seldom ate meals with her family because she was so busy.

Until the age of about 15 , she felt like her body could do anything that she wanted it to do. It never let her down, and gave her utter joy. She described feeling total mastery, control, and confidence. She remembered being on the dance/drill team, having a real strong image of fluidity; she would dream about it.

At about 16 years old, she had to quit swimming because her body began 
to let her down. She made excuses to herself and others in order to dismiss it, but it caused much disappointment and confusion. For the next four years, her physical abilities slowly deteriorated. High school and college years were the worst of her life. In high school, she continued to get slower and people started making fun of the way she walked. She walked like a duck because she became flat footed.

She went from joy and confidence in her body to a complete sense of shame. She stopped most activities. In ninth and tenth grade, she became involved with a Presbyterian social fellowship group. A lot in her life revolved around this Christian fellowship; she developed her spirituality and a deep personal friendship with Jesus. This, and her journal writing, which she started when she was 15 , helped her to cope with this "thing" she was experiencing, but did not have a name for.

She became more introverted and introspective, pouring her thoughts into her journals. She started to believe that if she became pure in spirit, she would not have to worry about the body. This she attributed to her Catholic upbringing. On the other hand, this focus also served to feed her denial. She had turned off most the things that were going on with her body, something to overcome; it was the enemy. She "tore herself to shreds" about this, generally feeling guilty and feeling that it was her fault.

After graduating from high school, she worked as a maintenance person cleaning bathrooms at a Christian camp at Yosemite for the summer. She described it as a very humbling experience, for she had to really struggle to get around.

By the end of her first year at college, Participant Number Three felt 
hysterical. Her friend insisted that she call her mom, but she felt that this sounded like death to her. She had this "shameful secret." It was then that she discovered that her sister and brother were having the same symptoms and they were all to go to Stanford for a work-up. She felt both angry at her mother and relieved at the same time, like it was a "coming out." When she received the letter from Stanford after her assessments, she learned there was nothing that could be done to treat this form of muscular dystrophy. She went out on her balcony and faced the woods and wept. She felt, however, that she went up a notch in her coping, because she had a name for it. Because she did not have to hide it anymore there was an incredible release for her. Previously there had been much angst and total suffering, being "in the closet" about it.

She realized she had been depressed and had gained 30 pounds. Her psychology teacher allowed her to do her undergraduate thesis on interviewing a person with a disability so that she could learn to cope with this new life with a disability. She started volunteering at Santa Rosa Center for Independent Living where she met and interviewed a friend who was the one who introduced her to the dance troupe about ten years later. She became familiar with the independent living movement, and issues around disability such as federal regulations for access. She set up an informational library and published a newsletter for the Center that summer.

Ever since she was in Girl Scouts and volunteered with a camp for severe cerebral palsy, she had been fascinated by people's different movement patterns. She focused on the connection of movement to emotions for her 
thesis, which had a very deep effect upon her. It became a personal quest to view her own process and concepts. She also continued to write in her journals during this time. In 1980, she graduated and started working at the Center for Independent Living as a peer counselor.

It was then that she developed a wonderful and intense relationship with a physically disabled man whom she described as a "mover." He taught her about disability, energy, coping and adaptation. He took her out on "wheels," where he would go wheeling and she would walk using two big leg braces. She then lost the stability in her knee joints and had lots of pain over the next three years while living with this man. He supported her experimentation in using a wheelchair. She then began to see her love for dance because the wheelchair was "freeing." She could sit down and move smoothly, not trip, not fall, was able to bend over and pick up something without falling, with no pain. The wheelchair represented greater mobility for her. The wheelchair was freely accepted and not pushed on her by any therapist or doctor. Her initiation into the wheelchair was a form of dancing. She and her friend would choreograph little dances while wheeling down roads, singing tunes.

The graceful movement was automatically just there; she always loved this activity and wrote poems about it. She and her friend would laugh with delight. She felt that she was in the right place at the right time, being able to play with the wheelchair, like a toy, before she actually had to use it. (Her boyfriend's wheelchairs' even had names.) This turned out to be a positive experience for which she is forever grateful. Later, she moved to a power chair because she knew she wanted to attend Berkeley and would need it on 
the large campus. She noticed a difference in the way people treated her, either not looking at her, or treating her overly nice. Luckily, she spent most of her time around other people who were studying to become social workers. The best of them were able to immediately deal with her as a person. She still encountered many accessibility problems while trying to socialize off campus. She kept in touch with her friend and they would go on wheels on pathways such as Point Reyes, both in their power chairs. Her joy stick on the control gave her ultimate joy; she still loves it. She stated, "At times, I still scare myself when we attempt wheels at these incredible places; it is all about mastery in terms of movement."

Between the years of 1983 and 1991, she was going to Berkeley and getting her social work degree while learning to get around as a disabled person in a wheelchair. She stated, "While I was studying and working, I was not dancing or doing anything physical, an incredible dry spell." She secured her first job at an Adult Day Health Center. For two years she drove to Marin and it was more and more difficult to manage the pedals in the car. She saved her money and bought a van and had an incredible time trying to get Department of Vocational Rehabilitation to help pay for it.

Meanwhile, she still was not doing anything recreationally. She connected with B.O.R.P. and discovered her friend (another participant in this study) was working there. She tried skiing and sailing and other activities but felt they were all too strenuous on her shoulders. She also fractured her right foot, and had to take off work for a short time. She still would not apply for disability assistance, as she has never done so in the past.

In 1991 she had the good fortune to fill a spot in a dance troupe in which her 
friend was a member. She felt so lucky to be processing with the group and assisting to choreograph, that she wondered if it could really be happening.

\section{Fourth Participant}

Participant Number Four is a Caucasian woman, 38 year of age who is married and lives in a single family home in Willoughby, $\mathrm{OH}$. She is the director of a non-profit business and directs a wheel chair dance company which operates under the auspices of the Cleveland Ballet Company. She has an Associate of Arts degree in business with specializations in accounting, secretarial work, and marketing/public relations. She serves as an expert witness in Washington D.C. on Disability issues. Her physician has verified her diagnosis of spina bifida from birth.

Her story began in Cleveland, $\mathrm{OH}$, where she was born to a professional musician father and a professional dancer mother. Neither of them were still active in the theater; however, they reminisced about their romantic times with their children. Her parents met on stage while her dad was playing "Stardust" for her, the song to which they fell in love. Participant Number Four grew up with her mom pulling old costumes out of her trunk and showing old newspaper clippings. She described all the dances and their travels. It sounded so romantic and exciting to the participant. Those were the bedtime stories on which she was raised.

When Participant Number Four was born, the doctors did not expect her to live, much less ever to be functional and productive. Her grandmother told her parents not to listen to the doctors and to bring her home and give her lots of 
love. She had to have 10 operations as a child and was considered fragile. She had a very sheltered life. The dance was something that freed her mentally. She was raised with her cousins, and her mother would put her down on the ground and encourage the children to have crawling races around the dining room. She can always remember listening to music and naturally moving and rocking to the rhythm. Before she was 12 years old, she was walking with canes and braces. She would perform the Mexican hat dance for the nuns near where she lived. Later, she broke her legs 3 times and ended up being confined to a wheelchair. She remembers dancing so hard in the wheelchair that she broke off the wheel right. She has always had the "vision of a waltz," in a beautiful long flowing dress.

Her parents tried to send her to a school for the disabled, but she could not tolerate the emotionally disturbed children's inappropriate behavior. At age 7, she told the principal that she was leaving and never coming back. From then on, she went to "normal schools" with the help of her mother, who would be there to carry her up the stairs as there were no wheel chair accessibility standards then. She was an "A" student and majored in voice through high school, although she was too nervous to do anything with the voice training. She worried about how obvious her mistakes were in singing, but less so with dancing because it was easier to "cover up the mistakes."

After high school graduation in 1975 , she entered a very lonely time. She did not drive at the time because she did not know she could drive. She was very isolated and stayed at home for three years, feeling really "stuck." During that time she had a kidney removed. The doctors were amazed because she was up and around the house cleaning after only two weeks. She started to 
pull out of her depression and demanded that she be allowed to go to work. Her parents were not supportive because they believed it would be a "hard, cruel world." Also, she also believed her mom was relieved to "not be toting me around anymore." She swore, once she got out, she would enjoy herself and not stay at home. She wanted to be "out partying in the real world."

After key punch training, she landed her first job, with which she was "bored to death." She worked for a total of six months before her parents decided to move everyone to the country. There she met a policeman who became her friend, empowered her with disability resources and rights and taught her how to be her own advocate. She fought to get public transportation with lifts during an election year and won. Soon she started meeting friends and sneaking out to clubs. This is where she began dancing with a friend. It was well received, and she became hooked on "dance fever" competitions.

During this time, she landed a job through her "cop friend," and Center for Employment Training Agency (C.E.T.A.), at the Catholic Social Services. This became the foundation of a job as the director of attendant training and services for the local Independent Living Center in Euclid, OH. She moved out with a friend after buying her own car, against the advice of her parents. She told them she was going to take the risk and do it anyhow, because she did not want to look back when she was forty years old and be sorry.

She was very driven. She tripled her salary within three years. She started thinking like an entrepreneur and figured out a way to get a sponsor from Invacare Wheelchair, Inc. to help pay for her dance performances in the 
dance fever competitions and elsewhere. During this time, she had gained experience managing a non-profit organization, and her fund raising events were very successful. She also directed a play about disabilities that went on tour.

She established the strongest independent living center in Ohio, and was being sent to Washington D.C. to lobby with politicians about disability issues. In about 1985, she began to see the need for a performing arts program for the disabled. By 1988, she figured out a way to begin a non-profit agency specifically for promoting the arts with the disabled population.

She was virtually working two full time jobs when she saw a want ad from the Cleveland Ballet for a coordinator to produce ballets in Detroit. She applied and was offered the position. She intended to quit the Center for Independent Living if she could devote all of her time to dance and the arts, as she felt that this was her true calling. She "took it" stating, "They knew who I was when I came into the office, ... the disabled dancer." She felt they could relate to her because "the gay community feels the same isolation." She feels that there are a lot of similarities, a closeness there. They accepted her right away, and she was successful. She worked at that job for nine months, until her contract was up. Then she decided to work on getting her dance troupe more accepted in the arts community.

A real tuming point occurred in 1989. Participant Number Four received a grant from the Ohio Arts Council. She then saw opportunities to establish classes for the disabled in the School of Cleveland Ballet. She was hired as the outreach coordinator for the Ballet. She also connected with an artist's 
clearing house, for the purpose of giving lecture demonstrations nation wide. The disabled dance troupe became a sub-group of the Ballet. The participant felt as though the dance troupe was "her baby," and that she was excited about the mainstage performances that she produced 1 or 2 times year.

\section{Fifth Participant}

Participant Number Five preferred not to have too much identifying information mentioned to preserve her confidentiality. She is a white, single 35 year old woman who lives in a single family dwelling in the Oakland Hills. Her home is not completely wheelchair accessible. There is no ramp at the entrance. She has been disabled since she was 19 years old. She works as a teacher at a college nearby and as a recreational therapist. Her physician has verified a diagnosis of incomplete paraplegia.

Her story began in New York. She grew up being very involved in the creative arts, especially dance. She was lucky enough to have free or low cost dance lessons from a well known artist available to her while living in New York from age 5 or 6 , until the time she was hurt. She loved dance and was able to have tremendous exposure to all theater arts.

The most obvious change after her disability was that she could no longer be a dancer. While in college, she took dance lessons for enjoyment, but her life was altered. She was in and out of rehabilitation centers and hospitals for a few years with various surgeries. It was a grueling couple of years. She was desperate to find something physical to do. She finished her degree at Cornell University with an independent major in community services. 
She became involved, very early on, in wheelchair sports. The recreational therapist at the rehabilitation center introduced her to this activity. By the first summer after her injury, Participant Number Five began competing in wheelchair basketball and slalom. She felt that she was very influenced by wheelchair sports, which changed her self-perception about feeling physically confident again. It was a positive experience which allowed her to see the wheelchair as freeing, as opposed to limiting. This was very important in her process. She did grieve, but did not see the wheelchair as the object of hate, which many people do.

She moved out to Berkeley, $\mathrm{CA}$ at age 21 , two years after the accident. She did not offer a reason why she left New York. This progression led her to start a theater company with a friend. After that it became a "community process." The participant dropped out of the company after the community of women that became involved with it basically took it over and it no longer suited her needs. It evolved beyond anyone's wildest dreams and is in good shape even now, but the growing pains were very difficult.

Participant Number Five decided that her heart had really been broken about not having dance and that was the thing she longed for most. Her first foray to return to dance was through choreographing an opening ceremony for a hundred able-bodied women at a spiritually oriented retreat. She remembered that it was "very wonderful and powerful." She repeated this experience again the next year, only this time from a wheelchair because she had sprained her foot. She stated that it was even more powerful to choreograph a piece which was inclusive to all different kinds of people and have it very well received. 
As soon as she became aware of the disabled dance troupe, she really wanted to be part of it because she saw this as an opportunity to apply her dance skills in practice. She remembers the first time that she saw the troupe. She thought her heart would break. It was like a dream had been taken away when she broke her back, and there it was returned to her in the troupe. She expressed her interest to be in the group many times, but was not invited to join initially. She really had a chance to see something about the politics in the disabled community. She stated, "There is a lot of competition, and a lot of people preventing others from having opportunities related to petty conflicts that could be easily resolved," and that "it is hard to be successful in the disabled community because there are not a lot of options." Eventually, she was permitted to join the dance troupe.

She worked with the troupe for a while and performed. There were many organizational problems as roles were not clearly defined. There were also communication problems and personality conflicts. At some point, Participant Number Five became the identified scapegoat of the troupe; the one who had different ideas, the one who wanted to do things differently. There were possibly other dynamics involved, as well. She was asked to leave the troupe. That is her story. It was "pretty depressing," and it devastated her.

It has been pretty hard for her to recover from this ordeal, and it's been a long, slow process. There are a couple of other people performing dance with whom she has "hooked up." Soon after she was asked to leave the dance troupe she suffered a traumatic brain injury. Luckily, it has not left her with many deficits. She is able to return to work fuil time and is getting ready to dive back into the dance world. It has taken years to heal from the psychological and 
emotional damage the experience of rejection caused. She stated while she was with the dance troupe she learned a lot. She felt that it was the gift that she received from them. She stated:

So this is a funny piece of my history. It's had a very negative effect on $\mathrm{me}$, as well as a positive effect. Positive in that it showed me a possibility, negative in that there was so much personality, character assassination, and limited opportunity, and power struggles, and competition, and indirect communication... and I think, ultimately, some real meanness. It had a pretty heavy effect, negatively, for a long time. I feel I'm just recovering from the whole experience. Actually, seeing them again was interesting for me. It said that I had really moved on, as a choreographer.

\section{Sixth Participant}

Participant Number Six is a 37 year old woman of Chinese descent who lives with her parents in a beautiful home in the hills in El Cerrito, CA. She is single and receives S.S.I. payments for her income. Her mom provides the attendant care that she needs. The home is completely wheelchair accessible. She has a Masters degree in Linguistics from Fresno State University and a Bachelor's degree in English Literature from Taiwan. Beautiful sculptures of busts of people whom the participant knows that she has made herself were at various locations around her home. Her physician has confirmed her diagnosis as Polio with restrictive lung disease. The onset of her disease was at 18 months.

Her story began where she was born, in Taiwan, and lived a very isolated childhood. She developed polio at 18 months. She enjoyed painting, drawing and doing crafts. She really enjoyed reading about places and things she did not know, because it took her places that she could not go. She does not 
remember anyone in particular introducing these activities to her. She felt isolated and did not identify herself with other girls who played with dolls. She did not have a doll all the time growing up; however, she enjoyed making paper dolls, and designed paper clothes. She would line them up with their clothes on them.

All of the children in Taiwan who had polio lived in a boarding school during their school years. They were taken to a segregated classroom in a public school. Participant Number Six lived in the first school for 6 years and then moved to another boarding school where she stayed 3 years. It was hard to be away from her family, and the other children at the school were jealous of her because she was an excellent student, very talented, and the teachers would rave about her performance. She was a loner. She played only with the small boys because she did not like the girl's games, such as dolls, gossip, or movie stars.

Participant Number Six stated: "All of us disabled children were told we were lucky to be going to school and that we were expected to pursue a vocation such as accounting, and I never wanted to be an accountant." She was then told by some relatives she should be a nun at a Buddhist Monastery, which was common since "you had no use as a woman." Or they would say "since she can't walk, maybe she could be a writer."

She was living at home during high school which was very stressful and competitive. She would go to school at 6:30 a.m. and not come home until 7:00 p.m.. She had no time to make friends because she studied all of the time. There were 100,000 people fighting for less than 20,000 places in college. 
The girls were segregated from the boys. She chose Science and Engineering as her major for college. There were few women in that. The Science and Engineering Department had lots of stairways at the college so she was told by the department head the first day of college "I can't take you, but you can have your choice of any of the other majors."

She transferred to literature because it was the most accessible and she had friends from high school who could be recruited to assist her with her mobility problems. She tried very hard to fit in . She felt like "a hard fighter" because literature was not her "thing." She finished it thinking "I just have to get through this." She was living in the dorms with the rest of the freshmen. These were horrible times as her classmates took turns pushing her in a manual wheelchair and some of them did not hide their irritation about "having to do it." It was a burden to them. But, she went through it because "without it she would go no where, disabled and a woman." She had to achieve something "to be better." She did manage to make friends after she joined a Christian fellowship group. She stated, "They were loving people and she felt accepted."

When she was a senior she moved out of the dorms to an apartment nearby campus with a few of her Christian friends. They were happy to provide her the assist she needed to get by. Things were better for her accept for now the developmental tasks of the young men and women was to begin to date and go to dances. She was never sent flowers or shown any attention by anyone, so she began to "question whether she was a girl, or that she must be very ugly or something."

Also, she felt suffocated by the society. She was not able to get a job because 
of discrimination and because of people's attitudes toward the disabled.

Overprotective people would say "Oh, where are you going? Let me help you...." while she attempted to go out for a walk alone. Then they would grab her arms. After awhile she gave up trying to go out, even to take a walk. She was at home all the time and she became very depressed. When all of her friends were getting married, she felt left out and hopeless.

She then got very determined as she really wanted to get away from the environment in which she was living. At that time, her parents were in the United States and they wanted her to join them. She decided to move to the United States and be a good Chinese daughter and please her parents by going on for my Master's degree in Linguistics at Fresno State. Her parents came to Taiwan to help her move and get settled in a dorm at Fresno State. She was planning to return to Taiwan after she finished graduate school, but she was also hoping it would lead to something else. It did, she decided not to return after she realized how inaccessible it was, how they treat women, especially women with disabilities.

She taught English as a Second Language classes for about two years, both before and after she graduated from the Master's program. She then experienced a medical crisis where she was hospitalized and almost died. She experienced post-polio syndrome and her muscles became weak, especially around her lungs and diaphragm. She was placed on a forced air breathing machine while she sleeps and was told to quit teaching. This was when she got into art. She never had the time to really explore it before.

A friend told her about the adult education art classes and she began taking painting class. She immediately loved it. Her busy life had nearly pushed away 
these loved childhood activities. Unfortunately, the classes were cut due to lack of funding, so she decided to relocate to live with her parents in the bay area and take art classes there. She met her close male friend at painting classes when he accidentally took her adapted easel and she asked to retrieve it from him. This is the close friend with whom she now dances in the dance company where they both are members.

She then bought a piano, and her piano tuner was a dancer and told her about opportunities in that community for disabled dancers to dance. He convinced her to attend a local "dance jam" and it was there that she was shocked to find that there was actually a way one could dance in a wheelchair. She thought it was beautiful, but was too terrified to join in. She sat on the sidelines and drew pictures of what she was observing. The second time she went her curiosity gave her the courage to try it. She had never moved with music at all during her life. It was very challenging because she was so scared. After a while it felt not only comfortable, it was a new release for her creativity. It felt like, in some way, she was liberated. For the first time in her life, Participant Number Six was able to move and express herself and her emotions. When she was asked to express certain emotions like sad, depressed and angry she realized she feared anger, but never had expressed it, never had a chance, and had not a clue of how to do it. She had always been a "good girl," never losing her temper. All of the others in the class were yelling with pained looks on their faces and she said, "I can't yell, I've never yelled in my life." It felt weird to her, but she started out copying the other participants in the class. 
Participant Number Six stated:

you have to be a tough spirit and daring to really convince yourself that... and I was really scared...l can't make angry faces and scream. You know, you have to be honest about who you really are and vulnerable, exposing yourself....It's not just the physical [barriers] at all, more mental....at about the same time in my life I began to see that it's not just the physical part. So much of a person is portrayed by the spirit, by the soul.

A short time later her piano tuner friend took her to a performance to see her artist friend dance. They arrived late and the show was waiting for them because the theater was not wheelchair accessible and she had to be carried down a flight of stairs. The artistic director spotted her being carried down the stairs and was struck by the expression of courage on her face despite everyone in the audience staring. He immediately knew he wanted her in their dance troupe. He asked her to join after he watched her and her artist friend improvise on the dance floor and she has been dancing with them ever since.

\section{Results}

Question \#1a) What did the participants do for optimal or selfactualizing activities before they became disabled, and as a child?

The most common response was a love for physical activities, especially sports and dance. Creative arts and music was the second most common response. There was a difference between the women who acquired a disability later in life and the two that began life with one. The four women with an acquired disability all closely approximated one participant who stated that she had a concept of herself as an athlete. Three of the four women also discussed the importance of the development of identity in being associated with the 
peer group that they were experiencing the physical activities. These peers and parents were part of their "world" and were their known support system up until the point of their onset of the disability.

The two participants who were disabled as small children were kept away, (shielded, or protected by their parents), from other children and were left to play by themselves much of the time. They were raised in what Kielhofner (1985) described as the "the sick role" (p. 331). They were thought of as being lucky to be alive as few children survived their diseases at that time (30 years ago). They were under the authority of the medical experts and considered "fragile."

All of the participants described experiencing a state of "flow" while involved in activities, such as the creative arts, dance, and sports (Csikszentmihalyi, 1990). Most of these experiences were when they focused on the "process" and not the "end product" of the activities, although they would get a "high" from the performance or end product.

\section{QUESTION \#1b) How did lifestyle changes and stress brought on by the disability affect their ability to engage in the above activities?}

The participants did not see themselves as being able to do anything that they enjoyed doing before, the activities which were avenues for pleasure and satisfaction (interests). They experienced a "degree of impossibility" regarding their perceived ability to engage in these meaningful activities which was felt $100 \%$ initially and then fluctuated at lower percentages the rest of their life. Kielhofner (1985) supports this finding that it may be impossible 
for individuals to imagine any possibility for success in the future, short of denying the permanence of the disability.

There appeared to be a process which all the participants with acquired disability had in common, which was more prevalent in three of four of these women. Clark (1993) noted these "rite of passage" phases, which her life-story research participant also experienced after her acquired disability. These phases, as outlined by Van Gennepp (1960) are separation (preliminal), marginilization (liminal), and reincorporation (postliminal).

In the first phase, there usually is an involuntary separation after the onset of disability and subsequent isolation from previous roles and activities. Kielhofner (1985) stated:

Persons forced to undergo loss of roles or changes in roles may experience a loss of identity that the roles provide. Decreased self-esteem may occur as they take on roles believed to be less important or as they lose roles. (p. 171)

The participants' motivation was affected as the participants discussed getting "hung up" on what they could not do, instead of what they could do. They stated that rehabilitation reinforced this as problems and deficits were always the focus. Socially, it was difficult for them to be around other disabled people, as this would reflect to them their own disability. They were slowly losing access to past groups and having to renegotiate and change relationships within continuing groups. Cultural prejudices such as the high value of physical beauty and self-reliance made it difficult for the participants to go out in public and enjoy the activities they previously enjoyed.

The progression in the marginalization phase actually lasted years, from five to ten years. The participants described this as the lowest point in their 
life. Two admit to contemplating suicide. They all used strong adjectives and verbs such as "this sucks," "it was very painful," that it was depressing and lonely, sitting in a wheelchair and not being able to be physical. Many of the participants had additional medical crises which brought them back to the hospital. All of the participants experienced this phase during their high school or college years. They were still trying to hang on to that little thread of identity which they had before their disability, but found themselves failing miserably. They felt that at least it gave them a purpose for a while and they were with familiar people and activities. They were depending on their families or close friends for both physical and emotional support. All but one of the participants felt their vocational and avocational choices were very limited, and that their only option was to go to college and major in business (or writing).

They were desperately trying to actualize their old dreams, but were not satisfied, perhaps because they were "operating off" of old beliefs, standards and values. Persons who experience sudden and permanent change in their physical status, must often reconstruct everyday life and life plans. A change in the volitional subsystem is mandatory for adequate adaptation (Kielhofner, 1985). None of these three women were able to achieve a "flow" experience at all during this phase. They described their attempts at physical activities such as wheelchair sports as satisfying and painful at the same time. This was because their physical power did not match their mental power, whereas before there was a connection between their mind and body during flow activities.

The other three women (and later, the above three women) experienced 
the end of their marginalization phase as a voluntary and abrupt change which they felt they needed. All of the women moved away from their families, two stayed in the same state and four moved across the country to the Bay Area. All were looking for a more disability-conscious area. They were now able to use their previously learned self-discipline and determination combined with their newly learned resources and adaptations from their disabled peers. A few of the women who acquired the disability learned how to use attendants for the first time, and were "forced" to re-engage in community activities in the public such as grocery shopping. They began to feel like they were forging an identity for the first time since the onset of their disability. This was the beginning of the "reincorporation" phase.

This "turning point" was a self-transcendence process when they decided to put faith in themselves and take a risk. It was then that the participants faced and felt mixed emotions about interacting with a new (disability) culture. The need to connect with services such as independent living centers and other governmental and bureaucratic groups related to receiving financial support, and vocational training, was, at first, not looked upon pleasurably. Within a short time, however, the women "found in other disabled persons a new and important reference group giving support and even political strength" (Kielhofner, 1985, p. 169). All of the participants have used the services of the independent living centers and four of the six worked for them either as a peer counselor, or, in higher positions such as director, expert witness and lobbyist in Washington, D.C. These women all became leaders and advocates for the disabled, and now seriously viewed their role as a representative for the disabled. 
These women appeared to this researcher to be "pioneers" who are carving the way and following their heart, or "bliss." It was on that path that these women spoke of being "chosen" for dance, again, as pioneers. This can be thought of as the validation of the self-transcendence that these women experienced. They used their creativity to not only adapt, and survive the turning point, but to evolve into something new and better, a more resilient and happier person.

Question \#2: What motivated the participants to choose dance as a worthwhile activity in which to engage after their disability?

The results related to the question were surprising to the researcher. All but one the participants felt that they "were chosen." Participant Number One stated that she felt almost like it is a "holy mission," like performing is a "gift," a service. It's her way of "giving back." She stated that she likes to be on the edge of things, a new frontier. She gets "high" from the experience. Participant Number Two was asked to join the dance troupe by a colleague from work and was given 24 hours to make her decision. Her past love for dance assisted her to be able to take this big risk. Participant Number Three always loved dance. She has been fascinated by people moving differently and wrote her undergraduate thesis in psychology on the connection between movement and emotions which she states had a very deep effect on her, like a personal quest. When she started dancing with the troupe she had gotten to a place where she felt like this was right and she needed to put herself out there and take that risk. "It felt so right." Participant Number 
Four was guided by visions from her childhood dreams. These included bedtime stories that her mother told her about her own professional dance career. She stated that, "I always said I (participant number four) was born with a spirit of a dancer. The arts are an avocation that chooses you, you do not choose them." Participant Number Six stated "Somehow I didn't choose dance, it chose me." Participant Number Five, however, stated her heart had really been broken about not having dance. The first time she saw the dance troupe perform she thought her "heart was going to just break, like a dream that had been taken away from her when she broke her back and there it was." She had a deep desire, or will to be in the troupe.

Diasio Serrett (1987) cited the work of Bennett (1966), that will (similar to the volitional subsystem) be seen in our commitments as either affirming or receptive. Affirming will is the aspect of mind which makes a commitment to make something happen; receptive will is that which receives and allows influence by ideas from another source or from other people (p. 94). It is possible that Participant Number Five exhibited more affirming will and the rest of the participants demonstrated more receptive will.

All the participants thought of dance as a natural progression into a physical activity as all were wanting sornething physical in their life and still were not getting enough. They all felt they had to take a risk and join in but were very glad they did because of the overwhelmingly positive reception they received from audiences. Also, the process of the dance allows for a very supportive climate for four out of six dancers, described as "it feeling like a family." 
Question \#3: How have the participants managed to reclaim or

develop this positive, creative, use of their bodies for a "total"

engagement in a "flow" activity such as dance?

The process is quite beautifully explained in Participant Number Three's

journal entry written after one of her first attempts to move or dance in

the traditional way:

This is a journal entry that I wrote when I was at Dominican college, it was my first year there. It was 1978, and that was a little over a year or a year and a half after I had actually gotten the diagnosis of muscular dystrophy. I was taking this theater improve class at the college. I was learning a lot, and here is what I wrote one evening after a class. "Body space...enjoy it, it's yours. And you can do with it what you want. You can stand perfectly still and feel the air of that space being taken into your body and let out again. You can feel the perfect balance of a straight strong spinal column or you can move through that space around you and leap and run and stretch out your arms to encompass all that you can. You can shout out through that space. You can make your presence known to someone else in their own space. You can become aware of other's space and how they use it as an expression of themselves. I have body space. It is mine and I enjoy it. But I'm not able to do with it what I want, totally that is. When others are running and leaping through space, expressing their exuberance, how shall I express my passion for the space that I occupy? The space and freedom of potential movement. I can be introspective about my space and reflect upon the space my body occupies right now. Not in the next flying leap. I can be quiet, and grieve, and picture my body as displacing air and space. I can move slowly through my space, but with no less exuberance and squeal with the delight I know of being able to move. (period) But I must be honest, I felt the loss of exuberance (limitation), a certain quality of exuberance about my body space was gone. Was this because I was aware of other's expressions, and how they better expressed what I was feeling, but could not express? I find it easier and myself much happier when I substantiate my exuberance through my body space alone. My expression is necessarily different than others. Why do I feel the ugly burden of "normal"? Do I not accept my expression when in the presence of others? (limitation) It is a physical fact and the concept of body space can be a very physical one. But exuberance is not necessarily physical. It is emotional. But how do I express it without... when the requirement is to express it physically then, of course, I am limited. Today, in class, I could not fill the requirement. I felt inadequate because of that requirement. God save me from internalizing requirements like those! 
This process is termed "clarifying of standards" by which clients judge themselves and is discussed under the personal causation component of the volitional subsystem. Kielhofner (1985) stated:

...the individual who recognizes the need to adjust values and goals will more readily identify personal rehabilitation goals and will be enabled to more fully adjust to the disability. (p. 172)

Other participants described the process of developing the occupational role of dancer in relation to the dance troupe as a form of "self-transcendence." When Participant Number One first started dancing, she felt like an outsider. There was a lot of processing required by the group and she would need the director or another leader to give "intention talks" in order to keep her focus. This process tended to elicit a lot of analysis and there still is a need for this process whenever there is frustration. When she danced, initially, she felt vulnerable because it "really puts your disability out there for all to see." Once she got past this frustration, it felt exciting and challenging. As a result, she found a way to "do what I have to do."

She calls this "the core process," and states when the dance troupe choreographs, all of them decide what gets put in the piece. They begin by improvising and trying to suspend their judgments. The energy level feels "free" and she is able to push herself through her moods. She now feels she is beginning to know ways to meet her personal standards. She is not stopped by challenge, and her courage is greater. 
Participant Number Two stated:

It was always there and I never had the opportunity to use it or express it...I guess I had to develop it. Not alienate myself from my body. To not hate my body, basically. Not see it as an enemy instead of a friend. So, that was a process over the years of coming to be comfortable in my body. Except for when I look in a mirror I still go "Eww...is that really what I look like." I have a real different mental image than what's really out there. I think it is more important the image that I have than what is in the mirror, because that is what I project.

She believes it is what is inside that matters, and that the process of learning to be resilient is making "somewhat of a conscious choice to decide you do not want to lead your life any other way." She does not want to be withdrawn into her body, in constant struggle with it, because "it's not fun." She keeps herself from slipping into that mode of thinking because of her strong knowledge, the strong experience of knowing what and how it feels to be constantly bringing herself down because of not being able to something. She stated that the horrible place in which such feelings place her, and the energy that it drains is terrible. When problems arise, she does not ignore them. She acknowledges them for a moment or so, and then makes a conscious choice to go on. She knows there is nothing she can do about it, but says on some deep level she does not think she ever will "accept it." She sees the reality of the situation and described "feeling sad over the whole sense of loss."

Participant Number Three described the process as embodiment, or coming home to her body and accepting it for whatever it is. It is a perfect vehicle for integrating movement with words as an expression of spirit. Her descriptions of how she feels while engaged in dance perfectly matched the criteria for a flow experience (i.e., totally conscious and within her body, complete 
awareness of how her body is moving in space, and in relation to the other dancers, sense of total peace). She called them peak experiences which makes her realize how wonderful it is that there is some way of experiencing that in this world [after being disabled]. During these times, she feels as though she could dance forever, there would be no tiredness, no gravity, no forces weighing her down. She feels as though she can grasp the infinite or divine in these moments. Her process with dance has now evolved to feel more ownership and trust with the dance troupe group.

Participants Number Four and Number Six (women disabled as children), both stated the exact words "Dance puts me in another world." The impact of their disability leaves them, dance is "totally freeing." There is no comparison, it is maybe like floating on a cloud or drifting in the sky. There are no boundaries, hardly any barriers. The minute they step on stage, all of their fears banish and leave them in total peace.

Participant Number Five described a process which was easy in solo physical activities such as slalom wheelchair races, but more difficult in activities with the dance troupe, due to trust issues that interfered with her comfort and satisfaction levels. Although she still described achieving a flow experience during performances.

In summary, all of the participants identified a love for physical and creative activities followed by an excitement because dance had great potential as a physical outlet. They then identified the importance of viewing the wheelchair as freeing and finding a safe and accepting environment in which to explore their potentials. They all identified taking a risk to join, but then feeling overwhelmed by the reception from the audience. 
This warm reception "hooked" them. Performances are a big "high" for all of the participants, but the process is equally important for four of the six women. All of the women discussed their vision of using of dance as a medium to change society's attitudes regarding the scope of expected roles for persons with disabilities instead of their perceived helplessness. They feel as though they function as representatives, or role models for the disabled population, and pioneers in dance for the disabled. All of them stated that getting involved in dance has been quite empowering.

Question \#4: How do the participants view themselves in the occupational role of "Dancer"?

Kielhofner (1985) has stated that individuals with function radically altered by disease or disability must acknowledge their perspective (however limited or deviant) of their competence, and relate it to the ability of another to recognize and appreciate the individual's performance from the same perspective. Physical disability confronts the individual with experiences that challenge and contradict a view of self as competent. The participants described the difficulty in viewing themselves in the role of dancer, and consequently, it is even more difficult to know that others recognize them in that role.

Participant Number One likes to identify herself to people as a professional dancer for the shock value. She feels that being a dancer is out of the scope of expected roles that most people have for a disabled person. Participant Number Two does not think she is a very good dancer, and would like to expand her repertoire of movements and take more classes to learn expression. 
Participants Number One, Two and Four become very excited about giving lecture demonstrations to children, both able bodied and disabled. They feel competent in the skills of giving the children opportunities that they did not have as children, showing them some tools to work with their own identity around being disabled. These participants described how it made them feel as follows; "It empowers people, it is a bright moment, it opens up their views of themselves." During the lecture demonstrations the participants felt competent in their ability to provide "a safe place or environment in which a person has the opportunity to transform." All the participants of the study reported that after both lecture demonstrations and stage performances able bodied people approach the dancers afterwards and say things like they "don't feel sorry for disabled people anymore." At times like these, the participants all voiced getting high satisfaction and feeling like they were fulfilling their unique purpose in life.

Participant Number Three stated that the issue about competence is a hard one, "It is really a double-edged sword." She feels confident in the process of creating something, rehearsing something, making something stage-ready, but she feels marginally competent in performing it. She feels the word professional has a lot more to do with integrity and quality and dedication than getting paid.

Participant Number Four felt the need to state that dancers with disability should not be compared with able-bodied dancers as wheelchair dancing is at an early stage of development, and that as a disabled dancer she "has a lot of catching up to do." She stated the artistic community in Cleveland now accepts her as a professional dancer whereas they did not a few years ago. 
Participant Number Five feels fairly competent as a dancer; however, she is not currently in that role. She feels she is ready to "dive back," or re-enter the dance world soon. As a disabled dancer, she feels that she has a tremendous amount of skill and competence. She feels she is really in the top group of performers in the country of people who have developed this skill. Participant Number Six feels that all dancers must work within their limitations the best they can, and that is what she feels she is doing. She is confident in what she can do, but there is a great amount that she feels she cannot do.

When asked to rate their competence regarding their role as dancer on a numeric scale, Participant Number One stated " $80 \%$ competent/ $20 \%$ what the hell am I doing." Participant Number Two stated, "60\% frustrated with her movement whereas it was $35 \%$ before." Participants Numbers Three and Five could not state any numeric value. Participant Number Four stated "6 out of 10." Participant Number Six stated "7 out of 10."

Overall, all of the women have had successful experiences performing on stage in front of a paid audience, therefore, this has enabled them to feel at least partially competent in their roles as dancers. They admit that it is still "pretty scary" to be on stage. They feel that their performing in dance is important, and they are glad to be doing it. 
Question \#5: Will the participant's recollection of any past occupational therapy reveal any attempts to address their occupational role(s) regarding creative play/self-actualizing activities in either their treatment planning or discharge planning?

Special attention was placed by the researcher on listening for information from the participants which might identify common social and environmental support systems utilized during any past therapy efforts in order to facilitate client participation in creative occupational behavior. Unfortunately, only one of the participants had the creative/play occupational roles addressed by the occupational therapist. In this instance, a woodworking kit for an easel was offered to the participant to make in occupational therapy, which the client found very purposeful as she needed one for painting while at rehabilitation. Further, it helped her to achieve her upper body strengthening goals. This participant was guided to use her body in physical activiuss by the recreational therapist, who was also in a wheelchair and who promoted wheelchair sports.

One participant did not recall ever seeing an occupational therapist previously, just a physical therapist a few times on a outpatient basis for braces and upper body strengthening. She was not happy with her therapy as the therapist "pigeon-holed" her to fit with all of her other sports medicine clients and the recommendations she was making did not work. The rest of the participants recalled unpleasant memories of their previous occupational therapy efforts in which the therapists basically lacked listening skills and 
ability to include the client in the treatment planning and goal setting process.

Only one of the participants had her creative/play roles addressed in occupational therapy. She was taken to a swimming class on an outing. All but one (i.e., making the easel) of the treatments described were traditional $\mathrm{ADL} / \mathrm{self}$ care and "meaningless" craft activities (i.e., making tile trivet ash trays when they did not smoke). Some of the participants were told they would never be able to dress themselves, so why bother working on it as a goal, yet within a few years they were independent. Another woman was told she would never make it as a public speaker, yet, within one year she was speaking at the state occupational therapy conference and confronted the occupational therapist who had told her this and was in the audience. This same woman remembers being "made" to demonstrate that she could cook her own meals and get out of bed, despite living independently (participant with spina bifida), and then told that she was not performing these tasks safely. It is possible that the women were challenged by being told these things. These treatments were administered 10 to 20 years ago, to put things into perspective; however, this is the image these women continue to carry about occupational therapy.

As in Clark's study (1993), rehabilitation was experienced as a rite of passage. The participants felt as though they were moved into disability status by their therapists, then abandoned. They felt like the push was made to get them to perform functional tasks and get them released. Two of the women were discharged without any follow-up therapy, and felt like the therapists had "given-up on" them. 
Question \#6: What do the participants believe health professionals (specifically Occupational therapists) who work in rehabilitation settings should know regarding self-actualizing roles and other aspects of the rehabilitation process?

First, the participants want therapists to be more honest with their clients and acknowledge their feelings that "yes, all is lost," and "it sucks." In order for therapists to do this appropriately, some background in grief processing is mandatory. The most overwhelming message the participants of this study gave was to "respect and honor" the grieving and reorganization process, which takes years. All of the clients felt they were being pushed and things were being crammed down their throats before they were ready.

Overall, the participants concluded that each person has her own process which must be initiated from the inside. Nobody can help one with it, although one can be inspired along the way by safe and non-threatening role models or programs. Five of the six participants felt that when they were in rehabilitation, they were not at the "acceptance" stage for these kind of influences and it was not until years later that they felt ready. As one of the participants stated so beautifully:

Everybody, as they attempt to re-engage, no matter what their disability is, or what kind of rehab, have their own personal space (or speed) and it's really important to tell them about, show them about [that], have peers to show them.... The whole thing about peers is so essential. I think every rehab hospital should have some kind of peer program ongoing....There really are some options or opportunities, and you can click with them now, or down the road. But you don't want to overwhelm people, but then to understand that they may or may not accept those options into their own life immediately because there is a whole emotional process going on around whether or not they feel like 
a cane looks good, or a chair looks good, or feels like it is part of their body image....People need mental health services, good mental health services in rehab...you can't talk technology to people. This person is not a machine....I do believe that rehab happens in stages and the fact is that in Westem medicine science, they want it all to happen in a very condensed period of time. So they'll deal with body issues, and practical, technical-type stuff, and feel frustrated when that person hasn't integrated it into their ability to function. And this is were, again, people are on their own time frame.

This participant is a medical social worker in a hospital, and was very articulate. All of the other participants in the study echoed what she had to say.

Another recommendation which all the participants voiced was that anyone who is to work in the rehab business should spend some time in the real world either with a simulated disability at least for one week, or follow a person around, long term, with a disability. This should be an absolute requirement. They need to get to that place, or wall, and realize what kind of frustrations they feel, looks they have to put up with, or attitude they deal with.

The participants felt as if therapists presented themselves as having to know the answers to everything; that when they do not, they take it personally and react as if they have failed. "They tend to want to cure everyone," stated one woman. The problem arises when the therapist interferes with the process discussed above, because of their need to "fix" their patients. Another participant felt some therapists and vocational rehabilitation counselors unknowingly limit the occupational choices of their clients due to their own biased attitude that careers in the arts is not credible and disabled persons could not make a living at it.

In summary, this chapter summarized the interview data, then synthesized 
and organized it in the results section, according to the research questions.

The six participants revealed a huge quantity of valuable data; only the pertinent answers to each question were presented here.

In the next chapter, common themes that repeated throughout the women's interviews are presented. These common themes will then be related to the occupational therapy profession in the form of implications and recommendations in Chapter Six. 
CHAPTER 5

\section{DISCUSSION OF COMMON THEMES}

In this chapter, themes that were common to all of the participants are identified, discussed and summarized. These themes were identified as the answers most often repeated for each question the researcher asked. Some of the common themes were taken from the information volunteered by the participants, especially if they were voiced with an emotional emphasis, or stated that they felt the particular point was very important. These themes provide the parameters in which the implications for the occupational therapy theory, practice, education and research are made.

\section{Honoring the Process}

The process that a newly disabled person experiences is a private one. It is "from the inside out" a few of the participants said. All the participants of this study voiced strongly that there should be more respect given to this process by health professionals and society in general. As discussed in Chapter Four, it is a long and emotionally-laden process. Viewed in the context of "rite of passage," the participants of this study appeared to be on "the right course." If viewed from this context, therapists would not have an urge to change them but would realize that they are on their own journey and it is all part of the process. This rite of passage viewpoint also assists in explaining the affective processes, the uncomfortable, lonely and inadequate feelings, and the initial resistance to what they "have to do," as part of the 
process. The unfamiliar psychological terrain is part of the package, and the mystery of what is happening to them is acknowledged.

When these behaviors (i.e. years of "resisting" the expert's suggestions and not restructuring or reintegrating into new occupational roles and activities while in the marginal phase) are viewed using the model of human occupation, criteria of occupational function and dysfunction are considered. The "adaptive" cycle is characterized by occupational function which represents states of optimal arousal and involvement in the environment. The continuum of occupational behavior is represented in three levels: exploration, competence and achievement. The dysfunction end represents the opposite tendencies: inefficacy, incompetence, and helplessness. As a result, one would describe the participants of this study as having moved from the "maladaptive" cycle during the separation and marginal phase to the adaptive cycle in the reincorporation phase. These cycles are not referred to by Kielhofner as static states in the human system but are recognized as dynamic [cognitive] processes.

This label of "maladaptive," however, has a negative connotation which this author feels should be avoided in persons with acquired disability.

It is this author's belief that the participants need the time while in the "maladaptive cycle" to restructure and reformulate their volitional (and habitual and performance) subsystems. It might appear to rehabilitation professionals as though these persons were in denial and in dysfunction, which would usually prompt efforts to "move them" toward function. This is perhaps where the participants felt judged and that they had the "stuff pushed down their throats" during rehabilitation efforts. 
On the other hand, if health professionals viewed this process as "normal" and "pre-adaptive," then they might prevent clients from feeling like failures and "beating themselves up" emotionally. It was during these times when the participants felt like they were going crazy and were depressed. They were relying on their affective feedback because their cognitive feedback still did not make sense to them (i.e., reorganizing their volitional subsystem, their beliefs, etc.) It is during these times that the participants fluctuated between operating on a cognitive (rational, or conscious) level and a affective (emotional, or unconscious) level. As one gains insights, or re-clarifies standards, the emotions which drove these issues to the surface subside. If acknowledgment is not given to affective processes (feedback), the person feels devalued, as it is part of their essence.

Moreover, the participants of this study (5 of 6 ) felt the choice to enter into the dancer role was not totally a conscious choice. If they were not open to their unconscious, or affective processes, they might not have known it was the right thing to do, to self-transcend, or to "follow their heart."

\section{Feeling "Chosen" in Their Dancer Role}

The concept of role was used as a central perspective while viewing participants' past history with present function. Role reconstruction, or development, as discussed previously, took years and during that time a very important process took place (above). In the model of human occupation, emphasis is placed on adaptive skills and behavior necessary for role reconstruction; however, this author believes that the affective 
processes are equally important. This affective information functions as the participant's only feedback mechanism until the person can make integrated sense of it, on a conscious level, or until the volitional subsystem is reorganized (as discussed above). This researcher proposes that it was precisely this process that gave them the strength, or resiliency, to go beyond the ordinary and find the path which would lead them to their unique purpose; to tap into their creativity and evolve away from the status quo, or what society expected.

Kielhofner (1985) has stated that the volitional subsystem governs all operations of the system and is responsible for choosing and motivating occupational behavior. This author believes it is not always a conscious choice, as was evident in this study. Out of chaos created by their disabilities came the turning point (Capra, 1982) of self-transcendence which put them in touch with their spirituality. This was evident in the comments such as "It's a holy mission," "a gift," as reported in the results section of Chapter Four.

\section{Finding an Identity as a Disabled Person}

After a person becomes disabled, a new sense of who they are must emerge. The participants who were disabled as children discussed this issue. There appears to be a limited choice of healthy environments from which a disabled person can explore and test out new occupational behavior which would eventually give them their identity. Participant Number Two stated:

getting involved in sports gave me less time to dwell on what I couldn't do anymore...getting an identity...I didn't really know 
what I could do or be as a disabled person and was starting to kind of have a place to fit in there.

\section{Similarity to Other Minorities}

Kibele (1985) cited other authors, DeJong (1979) and Vash (1980), who have compared the experience of persons with significantly limiting disabilities to that of racial and ethnic minorities who have struggled to achieve equality. Kibele's participants related experiences that confirm those of this study. The participants in this study have experienced the same isolation as have other members of other minority groups and cultures. One participant felt as though the gay members of the dance company hired her because they identified with her struggles and commitment to pursue her dreams despite adversity (i.e., non acceptance) from society.

All of the participants had an initial resistance to being classified with other disabled persons, as "it reflected their disability back to them." However, once they did immerse themselves into the new culture with an attitude of openness and receptiveness to learning, they felt it was an empowering experience. As in Kibele's (1985) study, all of the women in this study experienced a sense of freedom and independence living outside of their family of origin homes, and had their consciousness raised about their rights to equal access as disabled citizens. With the two women born with disabilities, this experience of freedom has increased their boldness and certainty regarding their needs and rights, like that of other cultural minorities. 


\section{Need for Safe Environment to Explore Physical Abilities}

The need for a safe environment to which people can come who are disabled or not possessing the ideal body is essential to the process of engaging or re-engaging in dance or other physically-oriented activities. All of the participants discussed the huge risk they felt they were taking when they "went ahead and tried these activities." The fact that where they were trying dance in an accepting and supportive environment, socially, physically and culturally made the difference. They felt that what is offered in "the real world" is unaccepting and at times alienating.

The participants described the task at hand during this process as "getting along with this body," then learning to find pleasure, or "flow" again with it during meaningful activities. Achieving flow after loss through disability is viewed as more difficult because physical activities are tinged with a sense of loss.

\section{Sense of Loss Ever-present with Sense of Joy with Physical Activities}

All of the participants spoke of the mixed emotions they frequently experienced while approaching a "flow" experience with physical activities, especially dance. One participant described it as follows:

It's only been in the past few years that I've come back to a sense of who 1 was then [when she trusted her body and it gave her joy]. And even though I get around differently, it's that persistence of memory....it's incredibly satisfying, but it's tinged with something very new in some respects...sadness and loss. 
The key to this insight is that the dancers learned to acknowledge this sense of loss and sadness without giving in to despair. It took all of the dancers a while to develop this ability, as initially it would "get them down." The dancers attributed this ability to acknowledge loss without giving in to despair as a testament to their resiliency. The loss is not something they "accept" on an emotional level because it would be too painful, but on a cognitive level, as an "adaptation," or "just part of the situation." Again, it involves changes in their volitional subsystems, but feedback is still on an emotional level. This is also reflected in the following quote from one of the participants who was born disabled:

When I am involved in dance, the physical part, there is sadness because I know I can't do what I would like. The same pain lies in all the disabled hearts. But I focus on what $I$ can do and be thankful.

\section{Disillusionment with Rehabilitation}

The results of this study confirmed both Clark's (1993) and Kibele's (1985) findings regarding disillusionment. The participants felt that the activities in which they were asked to participate in rehabilitation were not very meaningful and that the rehabilitation process pointed out their limitations. As in Kibele, the participants felt let down, not in control, and like failures when they did not achieve the goals which were set for them. This author has observed that usually healthy professionals represent themselves as experts, which can result in the clients putting their destiny in their "miracle worker" hands. They hope to be "fixed" and depend on the team to "do it." This expectation can be compared to the way one hopes a partner in marriage will 
make them happy, only to become disillusioned when the honeymoon period is over and happiness is fleeting. All of the participants recommended that more peer counseling be offered during the rehabilitation phase, as this would allow for more sympathetic listening ears and less "expert" advice.

Finally, rehabilitation professionals need to examine their attitudes regarding the credibility of and potential for creative and performing art roles and activities for clients. As one participant stated:

It is important that rehabilitation services stop limiting the occupations that people with disabilities can be involved in. I've been fighting with them right now. They do not see dance as a credible means of a career. I say they are making a judgment. There are people who can be paid, as myself, in the arts.

\section{Process of Story Telling Feeling Good and Therapeutic}

All of the participants voiced voluntarily during the interview that it not only felt good to tell their stories, but it was therapeutic as it helped clarify their issues and conflicts on a cognitive level, and put things into perspective. This method could very well be used to assist clients to reorganize their volitional subsystems, and integrate their affective and cognitive processes. Clark (1993) also found storytelling to be therapeutic in the life narrative of a stroke survivor's account of her personal struggle for recovery.

Clark described the process as follows:

Soon after we had begun the interview process, Penny realized that the sessions were therapeutic because they gave her a chance to reflect on her situation "with another person who has insights of her own into this, who is well-read, intelligent and sympathetic...but not someone who pities me or just feels sorry for me or is trying to change me.."..We agreed that recomposition, modifying a term used by Bateson (1990), best captured what had been going on. 
CHAPTER 6

PROFESSIONAL IMPLICATIONS,

RECOMMENDATIONS, AND

SUMMARY

The findings of this study related to the profession of occupational therapy are presented in this chapter. The first section discusses implications as they relate to occupational therapy theory. The second section presents recommendations for occupational therapy practice and education suggested by the physically disabled participants of this study. In the third section, suggestions for further research in occupational therapy are offered. Finally, the entire study is reviewed and summarized.

\section{Occupational Therapy Theory}

The attempt was made to base this research on the Model of Human Occupation (Kielhofner, et. al., 1985) as it is presented as a systems based frame of reference. The most significant finding was that there are areas lacking in the model, specifically in the volitional subsystem, which were pertinent to this study. One of the areas was the self-transcendence dynamic phenomena in systems (Capra, 1982) which was discussed in the literature review. Common themes which emerged from the study gave support to the theoretical explanation of why humans incorporate creativity into their occupational behavior. References by participants associated with feeling states, spirituality, and religion as one of the reasons for their resiliency appears to fit with the self-transcendence aspect of humans. 
Self-transcendence does not easily fit with the model or as part of the volitional subsystem.

Csikszentmihalyi (1990) stated that feelings and emotions are associated with creative activities and flow states and that it is healthy and rejuvenating to experience those feelings. All of the participants described these joyful feelings associated with their flow experience. In the model of human occupation, cognitive-based terms are used to describe the components of the volitional subsystem such as "belief that..., anticipation of..., how one interprets and views, commitments, internalized standards, one's disposition." These appear to explain preferences for activities and motivation for specific occupational behavior on a cognitive processing level. It does not appear to incorporate emotional components and their potential healing effects which clients in occupational therapy can tap. The meaning of the occupational activities is addressed on a cognitive level again, but not on an emotional level.

Affect of the client is not directly addressed in the volitional subsystem, other subsystems, or environment. Perhaps this is related to assuming the occupational therapist will automatically be observing for affect. Hopefully, this is not because occupational therapists believe that their clients are not in touch with their own affect states. Whether occupational therapists, as "experts" deem it appropriate or accurate, affect is still very real to clients and probably affects their occupational behavior at least as much as any other factor.

Recent findings in the psychonueroimmunology field (Hall, 1990) have suggested that when persons "listens to their gut" or "follows their bliss, or 
heart, or "answers the call," they are sick (or depressed) less often. The participants of this study reported feeling much healthier after they started dancing, and that dance did not drain them but gave them energy (was rejuvenating).

In summary, changes recommended in occupational therapy theory, specifically the model of human occupation, by this researcher are related to the common themes found in the study. This author proposes that occupational therapists may need to re-name the maladaptive-adaptive cycle of occupational function to that of a "pre-adaptive" cycle. Also, they need to acknowledge the process as both cognitive and affective as Fine (1991) suggested in her article on resiliency. Finally, the "pre-adaptation" phase needs to be recognized as a necessary cycle which allows the person who must now make drastic lifestyle changes to incorporate both conscious (mostly cognitive) and unconscious (mostly affective) processes (and ultimately changes in their volitional subsystem) in their recovery.

Occupational Therapy Practice and Education

Implications for practice and education are presented together in this section related primarily to the practice area of physical disabilities. Perhaps the most significant finding of this study was the overwhelming consensus among participants that occupational therapy students should have a period of time where they enter the real world of persons with physical disabilities and follow them around. This is recommended to be done with the physically disabled person teaching and showing the student, not as the occupational 
therapy student offering advice as an authority.

Suggestions were made to utilize already existing disabled student programs on college campuses as a huge untapped resource for potential "student teachers." The reason this interactive process should be set up with the disabled student/person as the "expert" is to teach the occupational therapy student to "listen" and not need have all the answers. The occupational therapy student has an opportunity to take the time to listen to the disabled student's stories. Once occupational therapy students are in the practical settings where their treatment time is restricted, they will no longer have the time to listen to the whole story, and they are no longer in the disabled student's real, natural world. This addresses the issue which Bateson (1990) discussed when she stated:

An encounter with other cultures can lead to openness only if you can suspend the assumption of superiority, not seeing new worlds to conquer (or "master"), but new worlds to respect (p.66).

This researcher has heard from other health professionals and clients many times, in practice, that the best therapists are ones who are either disabled themselves, who are married to someone who is disabled, or have a close family member who is physically disabled. They have essentially immersed themselves in the real world culture, of what it is like to really live with a disability in this society.

Another area affecting both education and practice is the incorporation of grief process education. It is critically important to honor the grief or loss process and realize the length of time it takes years for physically disabled persons to adequately reconstruct their roles. This is because of the tremendous demands for changes in both identity and skills. Change in the 
volitional and all the subsystems is essential to adapting to a disability (Kielhofner, 1985). Participants, in general, felt it was enough to have information and resources introduced to them, but resented them being "pushed down their throat" during rehabilitation.

Last, but not least, is the issue of when occupational therapy is provided to clients. Therapists may be in a dilemma between a slower-paced approach in regards to the time needed by a disabled person (to honor the process), and a reimbursement system set up to treat and discharge people as fast as possible. Quality of life is seldom considered in such reimbursement-driven decisions; functional outcomes are the usual focus. The push for an independence value system needs to be balanced in the medical rehabilitation model by offering an alternative to utilize attendants when resources will allow, as Kibele's study (1985) concluded. This allows clients to utilize their energy for more meaningful activities rather than be "forced" into the long, unproductive activities of daily living tasks which are prescribed.

The reimbursement-dictated health care system is set up to provide therapy during the rehabilitation phase. The World Health Organization has classified this as the impairment phase. It is ironic that the clients who are the participants in this study, and in Kibele's study (1985), reveal that what cccurs with them in acute rehabilitation actually points out their impairments. 5 of 6 participants stated "this is a very disempowering experience," for it facilitates the clients' ability to focus on what they can not do instead of what they can do. This author remembers learning in occupational therapy education to focus on what your clients can do, and not 
what they can not. In the rehabilitation setting, however, the medical model requires identifying the problems, on the functional skills which the client can not do, and to work on those.

All the suggestions for changes in occupational therapy practice and education were presented in practical terms which were taken directly from the study findings.

\section{Occupational Therapy Research}

This study concludes with a discussion of some directions for further research in occupational therapy. As with any study, replication is usually appropriate. Different geographical areas and populations could be utilized, although there is only a small number of physically disabled persons who are dancers. They are a unique group of people who are pioneers, and all of the participants of this study voiced that they were lucky enough to be in the right place at the right time. Further research might validate and extend these findings and (combined with the data from this study) may yield a better appreciation of the implications for occupational therapy practice and education.

Through repeated studies such as this one, and comparing the results, the theory base for occupational therapy can be further developed to include the self-transcendence aspects of the human. DePoy and Gitlin (1994) describe this process as "Grounded Theory," which systematizes the inductive incremental analytic process and the continuous interplay between previously collected and analyzed data and new information. 
Occupational therapy could also improve its effectiveness by continuing to gather data from its consumers and valuing their perceptions on how the therapists are providing care as well as the effect it has had on their lives. This has been recommended in numerous studies (Clark, 1993; Kibele, 1986; Schumacher-Davis, 1991) and by other occupational therapy leaders (Kielhofner, 1985; Yerxa, 1987).

It seems logical that one of the best methods to collect these data is through the use of life stories (Clark, 1993). Bateson (1990) stated that storytelling is fundamental to the human search for meaning. Using the life history method, comparisons could be made between persons born with a disability and those with an acquired disability. This study unintentionally had a mixture of both persons with acquired and congenital disabilities. Subtle differences could be detected among their life patterns. If studies were to be set up to better detect differences in the adaptation process, this author and Kibele (1985) are fairly certain valuable information would be discovered.

\section{Summary}

This study has offered findings that should assist the clinical reasoning of occupational therapists working with the physically disabled. The emphasis of the study was on the importance of considering the perception of clients regarding their motivation for and participation in creative activities and roles such as dance, and how rehabilitation professionals' attitudes regarding the credibility of these roles affects the treatment choices in the occupational therapy clinics. 
The researcher reviewed literature which discussed women and adversity, creative or optimal flow activities and the resiliency process in humans faced with adversity. Occupational therapy literature was also reviewed relating to similar earlier case studies. The need for a systems-based conceptual framework to assess the occupational behavior of this population was presented.

The researcher conducted 18 hours (tape recorded time) of interviews with six participants utilizing an interview guideline based on the interview questions. Questions were geared toward eliciting participants' self-perception regarding their involvement in self-actualizing activities, specifically about dance. This included information which would identify aspects of flow, resiliency, and self-transcendence, in addition to resources in the person's environment and culture, or society, utilizing a systems approach.

The data collected were analyzed in order to answer the research questions and to identify and discuss recurring or common themes. These categories provided the basis for the implications for the profession.

The research questions identified were answered as follows:

1a. The activities all of the participants engaged in as a child were physically oriented and creative arts. Most of them also loved outdoor and nature activities.

1b. After becoming disabled, they held a perception that these activities, which gave them the most joy and satisfaction, were now impossible for their participation. A long process evolved, which was related to "rite of passage" literature which included separation, marginality and 
reincorporation. Participants felt they were eventually able to achieve flow during their dancing, but only after drastic changes occurred in their attitudes, values, and standards.

2. Participants felt they were "chosen" to enter the role of dancer, that it was their destiny. They were following their heart, their love of dance, or their "gut" instincts. There were no motivating factors to chose dance as a worthwhile occupation that could be identified on a cognitive level, except for their "visceral memory "of what it felt like to dance or be physical.

3. The factors which the participants attribute to managing, reclaiming, or developing their dance role were:

a) clarifying the standards which they judge themselves as having a satisfying physical activity;

b) having a safe environment in which to explore their potential to participate in physical activity and/or dance;

c) viewing the wheelchair as "freeing" and not as an object of hate;

d) taking the risk to join; and

e) being "hooked" after the overwhelming reception from the audience after a performance.

4. All of the dancers felt "chosen" in their dance role.

5. Four of the six participants recalled past occupational therapy services as mostly meaningless and unrewarding. There was a perception of personal failure when goals of therapy were not met, as was also concluded in Kibele's (1985) study. One participant recalled her occupational therapy as worthwhile and meaningful and one did not have occupational therapy, just a few 
outpatient physical therapy sessions with which she was not impressed. 6. Recommendations given by participants included honoring the process which people go through after the onset of their disability during the time that lifestyle and role changes are mandated; offering more peer counseling during the rehabilitation phase, including more intense sensitivity training for occupational therapy students regarding physical disabilities out in the real world; giving grief counseling training to both occupational therapists and occupational therapy students.

Overall, evidence has been produced that occupational therapists need to reevaluate their attitudes regarding both the credibility of creative activities and roles in treatment planning and listening to the clients' affective processing during the assessment process while interacting with physically disabled populations. It is essential that safe and supportive environments are provided for clients to pursue their personal quests according to their own timing, and that the process is honored, whether therapists agree with it, or understand it. The system is not set up to support this practice, as it is driven by reimbursement. However, therapists can be more sensitive to the external presses and demands affecting them (i.e., shortened length of stays, ADL independence emphasis, etc.) yet, not contribute to their clients' feelings of discomfort or abandonment. Otherwise, clients leave rehabilitation as dissatisfied customers, feeling frustrated and remembering the experience as meaningless, as did the participants of this study. The Occupational Therapy profession would be taking a risk for the future if the issue of consumer satisfaction is not of prime concern now. 


\section{REFERENCES}

Barris, R., Kielhofner, G., Levine, R., \& Neville, A. (1985). In G. Kielhofner (Ed.), A model of human occupation: Theory and application (pp. 2-212) Baltimore: Williams \& Wilkins.

Bateson, M. C. , (1990). Composing_a life. New York, New York: Plume Publishers.

Capra, F., (1982). The turning Doint. Simon \& Schuster.

Clarke, F. (1993). Occupation embedded in a real life: Interweaving occupational science and occupational therapy (1993 Eleanor Clarke Slagle Lecture). American Journal of Occupational Therapy, 47, 1067-1078.

Csikszentmihalyi, M., (1990). Flow: The psychology of optimal experience. Harper \& Row, Inc..

Diasio Serrett, K., (1987). Improving quality of thinking and productivity in organizations. Sunnyvale, CA: Privately published monograph.

DePoy, E. \& Gitlin, L., (1994). Introduction 10 research. Mosby, Inc.

Fine, S. B. (1991). Resilience and human adaptability: Who rises above adversity (1990 Eleanor Clarke Slagle Lecture). American Journal of Occupational Therapy, 45, 493-502.

Hanna, J. L. (1988). Dance and ritual. Joumal of Physical Education. Recreation and Dance, 12, 40-43. 
Kaplan, K., \& Kielhofner, G., (1989). In G. Kielhofner (Ed.), Occupational case analysis interview and rating scale (pp. 5-23). Slack, Inc. New York.

Kibele, A., (1986). Directions for occupational therapists derived from the experience of adults with significantly limiting cerebral palsy: Five case studies. Unpublished master's thesis, San Jose State University, San Jose, CA..

Kirchman, M. (1987). Attitudes toward disability. Physical and Occupational Therapy in Geriatrics, 5(3), 51-62.

Marmer, L., (1991, July 22). Axis dancers give new meaning to the word 'wheelchair'. Advance for Occupational Therapists. I (29), 18-19.

Meyer, A. (1977). The philosophy of occupational therapy. American Joumal of Occupational Therapy, 31, 639-41.

Rogers, J., (1984). Why study human occupation?. American Journal of Qccupational Therapy, 38, 47-49.

Schumacher-Davis, J., (1991). An exploratory study of common themes regarding quality of life for persons with rheumatoid arthritis. Unpublished master's thesis, San Jose State University, San Jose, CA.

Van Gennep, A., (1960). The rites of passage(M. B.. Vizedom \& G. L.. Caffee, Trans.). Chicago: Chicago University Press.

Yerxa, E., (1987). General research questions. American Journal of Occupational Therapy, 41, 415-19. 
APPENDIX A

SAMPLE CONSENT FORM 


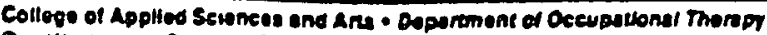

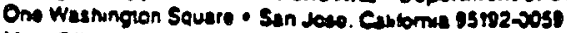

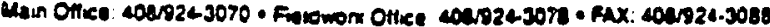

\section{SUTJECT CONSENTIEORU}

As you have diseussed with Thris, you are invited to participate in a stucty of the peresption you bold regarding your self-directed involvement in the occupacional role of a daneer in lodry's sociefy. I hope that the routts of roy sudy will better prepare bealth professionals, specially occupational therapists, w be roore aware of the importance of fosterizg conditions which facilizise reclaining or developing playful, or "elff-actuatizing" occlpational roles in addition to the more traditional self-care and commurity work roles. This. I believe would improve the adpatation and coping to the tremendous stressors imvolved with suffering a physically disabling injury or illnees.

You hove been selected as a possible participant in the sucty because of your being a member of AVIS dance troupe and your exprased arilingasess to communieate your thoughts and feelings about your experience.

If you decide to participate, I will meet you as a munast, dereed upon time and locasion, and pill be asking you questions aboun your past and present experience. Because I am ancious to hear 2ll that you have to say, I will bisten, wite down, and tape record the interview in it's entirety. I will be using prepared questions wtich might take as long as four hours to complete. This can be split into several days or weeks, as is necessary for either of us.

Your signanure (and iwitials) on this document also indicates your willingess to allow me to cend your doctor a letter requesting that he confirm your age and dingnosis. Fis/ier agreernent is necessary to make the rasuls more believable.

Afler I hrve identified and intervieared all of my subjects, I will listeen to all the tape recordings. I will analyze them and inierpret the result for my final paper. This will most biely cale up to one year. In the meantime, all data collected will be kept in a locked alle cabinet in my bedroom Afiet the study is complete, all the dats will be destroyed.

Any information that is oblained in comection with this study and that can be identified with you will remain confidential and win be disclosed only with your permission or 25 required by law. If you give your permission by rieging this document, I plan to diselose informacion you hrve given me regarding your experiences with, and pereeptions of having a plysical disability and being a dancer, and especially whas has enabled you to be able to do this in cody's society. However, no names will be mentioned, and I do not anticipste thas it aill be possible for anyone to identify you as distinguished from others in the study. 
Ily sndty witl be presented to the depacenent of Oecupacional Therapy at San Jose State

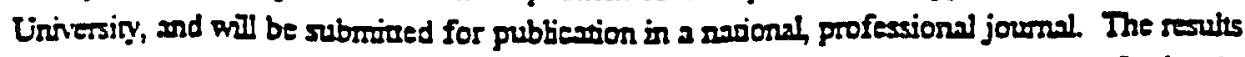
might also be presented at eicher state or artional Oecuparional Therspy (or other grofessional) conferences.

This sndy is in no wry connected with, nor will it be completed with the assiswnee of ary agerify where I have been previousty exaployed, or with which I an exrestly enployed

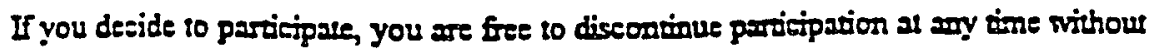
prejudiee. A copy of your bill of rights as a subject in this souty is artached to this form and you aill be given a copy of your signed conseot forsu to ketp also.

I eannot and do not guasentee or promise that you will recive any beatefis from this study. I xill be happy to share the results with you upon cormpletion Other than the tine you give to complest the intervier, there will be no cost 10 you. You will not receive payment for your paricipasion.

If you have ary quescions at arty time, feel free to contes me direety (408)448-0127. If you don't feel comforable diseussing your conceras or questions with me, for whatever resson. feel free to eall my paduase fealty advisor al Sen Jose State Universify; Dr. Karen DiasioSerrer (408)924-3075. For questions or couplains abous researth subject's rights, of in the event

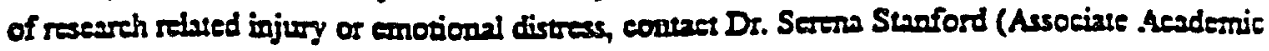
Viee President for Gradrate Studies) as (405) 924-2480.

BY SIGNLNG TFES FORMI AM GIUNG MY VOLUNTARY CONSENT TO P.ARTCIPATE DN THIS STUDY AND KAVE READ AND UNDERSTAND THIE DNORMATION ABOVE.

Dase

Dare
Signanre of Participant

Signaure of Researcber 
APPENDIX B

LETTER TO PHYSICIAN 


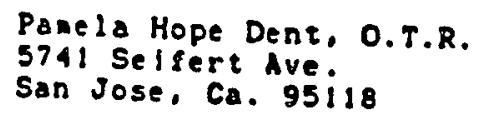

Harch 1. 1992

Physlelan's Nane

Address

Regarding: Particlpant's Nane

I an a reglstered occupaelonal therap!st, currently enrolled as a graduate student in the Departnent of Occupational Therapy. at San jose State Unlversity. In partial fulflliment of the requirenents for the Master of Percept ongree, I an complet Ing thesls. entitled The Perception of Flve Wosen ulth Disabllities of thelr Selfirected Occupatlonal Role as a Dancer In Today's Soclety."

I Intend to increase ayareness anong health professlonals, Including occupat lonal theraplsts, regarding the Inportance of fosterling conditlons which ulij facllitate reclalalng or developing playful or 'self-actualizing" cccupatlonal rojes in addition to the nore traditional selfthe adaptailon and cork roles. Thls, I bellev. illil Improve physlcally disabled in our culture.

I plan to gather data for ay descrlptlve study through extended. In-depth intervlews with flve Individuals with physlcal disabilities who are involved in dance. Your ny research. Please note her' has agreed to be a subject in

in order to increase the valldity of ay study, I need conflration of the diagnosis uhlch would classify her as beling physlcally disabled. If you are in agreenent. yould you specifled and date la the spaces provlded after you have any coment wat the dlagnosis is on the attached form: provide addresses gou wish: and requrn the form to ae in sedf-

If you have any questlons about thls request, I yould velcone your Inquiry at the above address, or you can call at (408)948-0127. Thank you for your attention to this
natter.

Sincerely,

Pamela Hope Dent, O.T.R.

Reglstered Occupational Theraplst. 
APPENDIX C

PHYSICIAN'S CONFIRMATION OF DIAGNOSIS 


\section{PHYSICIAN'S CONFIRHATION OF DIAGNOSIS}

Particlpant's Signature: I have read the naterlal provided for me by Panela
Hope Dent, $0: T . R$. regarding her research, and have agreed
to be a subject.

Physlclan's slgnaqure:

I have read the attached letter regarding the researi-h to be conducted by Panela Hope Dent, O.T.R.. and the above notlce of the wllingness of ny patient. B.D. to be subject in that research. I an in-" agreement that the primary dlagnosis for this individual is 
APPENDIX D

INTERVIEW GUIDELINES 
QUESTIONS

1. WHAT ARE SOME OF THE ACTIVITES THAT YOU REALLY LOVED, THAT MADE YOU FEEL WONDERFUL BOTH AS A CHIDD, AND UP TO THE PODNT OF YOUR ACCIDENT/DISABIITY?.

2. HOW DD THAT CHANGE AFTER THE DISABIITY ENTERED YOUR LIFE? HOW DID II AFFECT YOUR ABIITY TO ENGAGE DN ACITIIIES YOU JUST MENTIONED?

SAY MORE ABOUT........

3. WHAT LED YOU TO CHOSE DANCE (AGALV)?

4. HOW HAVE YOU COME TO DEVELOP THE USE OF YOUR BODY, AS IT IS NOW (NEW BODY) TO ENGAGE IN DANCE?

SAY MORE ABOUT WHAT IT WAS LIKE TO DO THAT (PROCESS)... BEGNNNDG, MIDDLE, NOW....

HOW WOULD YOU DESCRBE THE MOST MEANINGFUL (OR PEAK) TIMES YOU HAVE FELT WHIIE DANCING?

S. HOW DO YOU VEW YOURSELF NOW, DN THE ROLE OF PROFESSIONAL DANCER?

6. HAVE YOU EVER HAD ANY OCCUPATIONAL THERAPY?

WHAT IS YOUR RECOLLECTION OF PAST O.T. EFFORTS TO MOVE YOU TOWARD ACTTVIIIES THAT WERE MEANDNGFUL AND BROUGHT SATISFACTION TO YOU?

DURDG THE ACUTE PHASE?

DURDNG THE OUTPATIENT OR LONG TERM COMAMUNTY PHASE?

7. WHAT ADVICE WOULD YOU GIVE OCCUPATIONAL THERAPIST ABOUT THE REHABITTATION AND RE-ENGAGEMENT PROCESS BASED ON YOUR EXPERIENCE THAT WOULD HAVE HELPED YOU DN THE DEVELOPMENT OF LIFE ACTIVTIIES THAT HAD REAL MEANING TO YOU SUCH AS DANCE?

(i.e. HELD OUT A VISION THAT ALI IS NOT LOST, SPECIFIC PSYCHOLOGICAL AND/OR PHYSICAL THINGS TO DO..., SPIRTUAL... VISTTATIONS FROM...) 
APPENDIX E

SAMPLE "MIND MAP" 


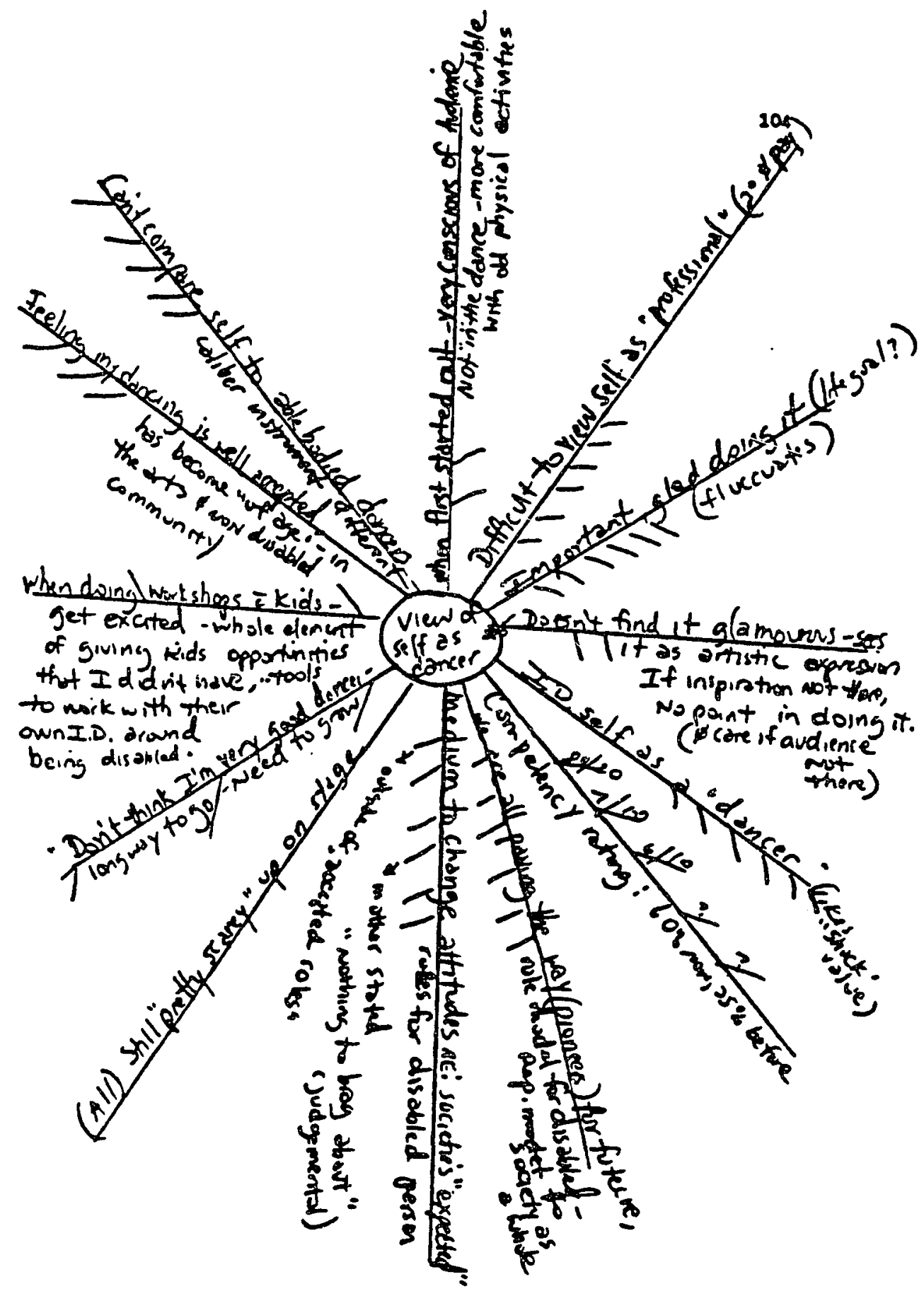

